\title{
Stochastic models for phytoplankton dynamics in Mediterranean Sea
}

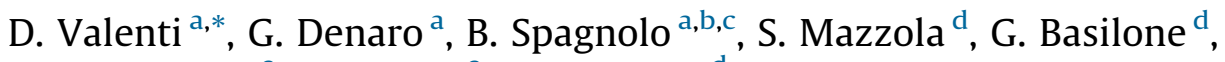 \\ F. Conversano ${ }^{\mathrm{e}}$, C. Brunet ${ }^{\mathrm{e}}, \mathrm{A}$. Bonanno ${ }^{\mathrm{d}}$ \\ ${ }^{a}$ Dipartimento di Fisica e Chimica, Università di Palermo, Group of Interdisciplinary Theoretical Physics and CNISM, Unità di Palermo, Viale delle Scienze, Ed. \\ 18, I-90128 Palermo, Italy \\ ${ }^{\mathrm{b}}$ Radiophysics Department, Lobachevsky State University, 23 Gagarin Avenue, 603950 Nizhniy Novgorod, Russia \\ ${ }^{\mathrm{c}}$ Istituto Nazionale di Fisica Nucleare, Sezione di Catania, Via S. Sofia 64, I-95123 Catania, Italy \\ ${ }^{\mathrm{d}}$ Istituto per l'Ambiente Marino Costiero, CNR, U.O.S. di Capo Granitola, Via del Faro 3, I-91020 Campobello di Mazara, TP, Italy \\ e Stazione Zoologica Anton Dohrn, Villa Comunale, 80121 Napoli, Italy
}

\section{A R T I C L E I N F O}

\section{Article history:}

Received 30 January 2015

Received in revised form 14 May 2015

Accepted 28 June 2015

Available online 4 August 2015

\section{Keywords:}

Spatial ecology

Marine ecosystems

Phytoplankton dynamics

Deep chlorophyll maximum

Random processes

Stochastic differential equations

\begin{abstract}
A B S T R A C T
In this paper, we review some results obtained from three one-dimensional stochastic models, which were used to analyze picophytoplankton dynamics in two sites of the Mediterranean Sea. Firstly, we present a stochastic advection-reaction-diffusion model to describe the vertical spatial distribution of picoeukaryotes in a site of the Sicily Channel. The second model, which is an extended version of the first one, is used to obtain the vertical stationary profiles of two groups of picophytoplankton, i.e. Pelagophytes and Prochlorococcus, in the same marine site as in the previous case. Here, we include intraspecific competition of picophytoplanktonic groups for limiting factors, i.e. light intensity and nutrient concentration. Finally, we analyze the spatio-temporal behaviour of five picophytoplankton populations in a site of the Tyrrhenian Sea by using a reaction-diffusion-taxis model. The study is performed, taking into account the seasonal changes of environmental variables, obtained starting from experimental findings. The multiplicative noise source, present in all three models, mimics the random fluctuations of temperature and velocity field. The vertical profiles of chlorophyll concentration obtained from the stochastic models show a good agreement with experimental data sampled in the two marine sites considered. The results could be useful to devise a new class of models based on a stochastic approach and able to predict future changes in biomass primary production.
\end{abstract}

(c) 2015 Elsevier B.V. All rights reserved.

\section{Introduction}

The analysis of the mechanisms responsible for the spatiotemporal dynamics of phytoplankton populations represents one of the most worth challenges for marine ecological modeling, due to emergent problems such as global warming and reduction of the primary production in marine ecosystems (Patti et al., 2010; Valenti et al., 2015). In fact, the changes in the growth of fish species observed in the oceans are mainly explained by variations in the chlorophyll concentration, which is a marker of the presence of phytoplankton communities (Jennings et al., 2001; Bopp et al., 2001; Cuttitta et al., 2003; Sarmiento et al., 2004; Schmittner, 2005; Weston et al., 2005; Kiorboe, 2008; Patti et al., 2010;

\footnotetext{
* Corresponding author. Tel.: +39 09123899037; fax: +39 09123860815.

E-mail addresses: davide.valenti@unipa.it (D. Valenti),

bernardo.spagnolo@unipa.it (B. Spagnolo), christophe.brunet@szn.it (C. Brunet), angelo.bonanno@iamc.cnr.it (A. Bonanno).
}

Karsenti et al., 2011; Melbourne-Thomas et al., 2013; Valenti et al., 2015).

During last decades, the modeling of dynamics of spatially distributed systems, such as marine ecosystems, has been carried out by following four different approaches (Durrett and Levin, 1994): (i) mean field theory, in which all system particles have equal probability of interacting with each other in a homogenous environment; (ii) patch models, where the space is divided in several homogenous patches in each of which discrete particles interact with each other; (iii) reaction-diffusion models, in which infinitesimal particles are distributed in heterogenous continuous space and the deterministic local nonlinear interactions with the environment are considered; (iv) interacting particle systems where a group of discrete particles, distributed in the space, is subdivided into a grid of cells in each of which the interactions between particles are treated explicitly. In this context, we choose the theoretical approach to be used in our work on the basis of the typical features of marine ecosystems (Durrett and Levin, 1994; Berti et al., 2007), which are 
characterized by: (i) the high cell concentration for all phytoplankton populations investigated; (ii) the absence of direct interactions between phytoplankton cells; (iii) the presence of nonlinear interactions between phytoplankton groups and surrounding environment; (iv) spatial heterogeneity of the resources which limit the growth of phytoplankton populations. These features indicate that only the approach based on the reaction-diffusion model is able to reproduce the spatio-temporal distributions of phytoplankton populations in aquatic ecosystems. Specifically, in this paper the analyses have been performed by using an advection-diffusion-reaction model, i.e. a reaction-diffusion model with a drift term, in order to take into account also the oriented movement of the phytoplankton populations (Klausmeier and Litchman, 2001; Huisman et al., 2002, 2006; Ryabov and Blausius, 2008; Ryabov et al., 2010; Vergni et al., 2012; Valenti et al., 2015).

It is worth recalling that the studies based on this kind of deterministic model do not consider the local stochastic interactions between the planktonic groups and the surrounding environment. Therefore, in recent works (Valenti et al., 2012; Denaro et al., 2013a,b,c), the vertical profiles of chlorophyll concentration in Mediterranean Sea were studied by using stochastic models, taking into account the random fluctuations of environmental variables, such as temperature and velocity field. This new approach is used to better analyze the real dynamics of phytoplankton populations, which are continuously exposed to random and deterministic changes in environmental variables. Indeed, it is worth recalling that marine ecosystems are complex systems, that is open systems characterized by nonlinear interactions between their parts and external perturbations (Goryachev et al., 2005; Maye et al., 2007), both deterministic and random, due to environmental variables (Grenfell et al., 1998; Zimmer, 1999; Bjornstad and Grenfell, 2001; Spagnolo et al., 2002, 2003, 2004, 2005; La Barbera and Spagnolo, 2002; Spagnolo and La Barbera, 2002; Valenti et al., 2004a, 2006; Caruso et al., 2005; Chichigina et al., 2005, 2011; Fiasconaro et al., 2006; Chichigina, 2008; La Cognata et al., 2010). As a consequence, the study of a marine ecosystem has to be performed by considering also the effects of random perturbations, which can be treated as environmental noise sources. Therefore, in order to better reproduce this nonlinear and noisy dynamics, and according to previous works (Spagnolo et al., 2004; Dubkov and Spagnolo, 2005; Bonanno et al., 2007; Valenti et al., 2007; Liu et al., 2008; Zeng et al., 2015), we consider in our models the presence of external random perturbations. In particular, in the equations that describe the dynamics of the phytoplankton abundance and nutrient concentration we insert terms of multiplicative Gaussian white noise (Valenti et al., 2012; Denaro et al., 2013a,b,c). This technique has been recently used to model population dynamics (Spagnolo et al., 2004), even if few authors keep to exploit an approach which includes terms of additive noise instead of multiplicative noise, inserting some constraints which prevent the population density from becoming negative (Liu et al., 2008).

The first models for phytoplankton dynamics have been devised by considering the light intensity as a limiting factor (Shigesada and Okubo, 1981; Huisman et al., 2002). This approach was likely inspired by the prey-predator studies (Liu et al., 2008; Tian and Zhang, 2013; Bengfort et al., 2014), which introduce the prey concentration as a limiting factor of the predator concentration. The crucial role of the limiting resources has been relaunched in recent works (Klausmeier and Litchman, 2001; Huisman et al., 2002, 2006; Ryabov and Blausius, 2008; Ryabov et al., 2010; Ryabov, 2012), in which the authors modified the reaction term to reproduce the effects of two or more limiting factors on the phytoplankton dynamics. This choice was suggested by the analysis of experimental data acquired in situ during the last decades. Indeed, the field observations showed the presence of a heterogeneous distribution of nutrient concentration along the water column, which is strictly connected with the nutrient uptake ability of the phytoplankton populations within the euphotic zone. Specifically, in aquatic environments investigated, it has been observed that the shape of vertical picophytoplankton distributions depends on the spatial behaviour of two limiting factors (Klausmeier and Litchman, 2001; Hickman et al., 2010; Beversdorf et al., 2013; Klausmeier et al., 2007), i.e. light intensity and nutrient concentration. These are responsible for the photosynthesis process within the phytoplankton cells, and contribute to select different communities along the water column (Huisman and Weissing, 1994). The reduction of the light intensity, as a function of the depth, associated with an opposing gradient of nutrients allows to keep a positive net growth rate only within the production layer. In particular, the position of this layer and the magnitude of cell concentration peak, for each phytoplankton group, depend on several biological and physical parameters (Fogg, 1991; Prézelin et al., 1991; Norberg, 2004; Hickman et al., 2010; Yeo et al., 2013). In general, environmental parameters play a critical role in the equilibrium of an aquatic ecosystem. An example of this is provided by the changes in physical variables, which modify the vertical profiles of the limiting factors, i.e. light intensity and nutrient concentration. These changes cause in the phytoplankton distributions a passage, during the same year, from a stability condition with a deep chlorophyll maximum (DCM) to another stability condition with an upper chlorophyll maximum (UCM), and vice-versa (Ryabov et al., 2010; Valenti et al., 2015). Moreover, some physical variables, such as temperature and salinity, can act directly on the production mechanism of phytoplankton biomass, modifying the spatio-temporal behaviour of the net growth rate within the production layer (Hickman et al., 2010).

In this paper, we intend to show how spatio-temporal dynamics of real chlorophyll concentration can be modeled, reproducing vertical distributions of phytoplankton communities along the water column in different marine ecosystems. The problem of effective models for trustable predictions of the primary production, i.e. phytoplankton biomass, in Mediterranean Sea and, in general, in aquatic environment, represents one of the major issues until now not solved. During the last years the main theoretical tool, used to face the problem of the spatio-temporal dynamics of phytoplankton populations, has mostly consisted in approaches based on advection-reaction-diffusion models, which describe: (i) biomass production (birth and death); (ii) active and passive movement in a preferred direction; (iii) diffusive motion due to the presence of turbulence along the water column. Many theoretical works analyzed the properties of advection-reaction-diffusion models, and the conditions under which different dynamical regimes appear, such as chaotic and oscillating dynamics, monostability or bistability of the chlorophyll maximum, role of different boundary conditions on the total amount of the phytoplankton biomass. However, as previously noted, any analyses have been never performed during last decades, with only few recent exceptions (Denaro et al., 2013a,b; Valenti et al., 2015), on the actual predictive skills of advection-reactiondiffusion models. In particular, no quantitative validations, based on statistical tests which allow to measure the agreement between experimental and theoretical chlorophyll concentrations, have been carried out until some years ago. The lack of a comparison between theoretical and experimental findings did not allow to check the ability of these models to reproduce real chlorophyll profiles sampled in marine ecosystems and, more specifically, in Mediterranean Sea. Recently a new class of models based on a stochastic approach were tested, by using statistical checks, as a tool suitable for the description of real spatio-temporal dynamics 
of phytoplankton communities. On this basis, hence, we review here some results on phytoplankton dynamics, presenting a selfconsistent analysis, carried out in two different real marine ecosystems, and based on different stochastic advection-reactiondiffusion models. In particular, we show how considering more than one population as contributors to the total biomass concentration allows to better reproduce the experimental chlorophyll profiles. Moreover, we show how the inclusion in the model of noise sources, which mimic the environmental random fluctuations, is crucial to reproduce the experimental chlorophyll profiles in a more precise way respect to the deterministic models. For this purpose, in the present work we discuss some findings obtained within the context of the spatiotemporal dynamics of phytoplankton populations in Mediterranean Sea, presenting in the last section new results obtained by a stochastic five-population model. Here oligotrophic conditions are guaranteed during the whole year and phosphorus is the nutrient component playing the role of limiting factor for the growth of the phytoplankton communities (Thingstad and Rassoulzadegan, 1995; Ribera d'Alcalà et al., 2003; Denaro et al., 2013b; Valenti et al., 2015). The theoretical approach is based on stochastic advection-reaction-diffusion models, which allows to analyze and reproduce the vertical profiles of chlorophyll a concentration obtained from data collected in two sites of the Mediterranean Sea, during different oceanographic surveys in the period from 22 August 2006 to 9 June 2007. In particular, the stochastic models are able to reproduce the spatio-temporal behaviour of marine populations belonging to the picophytoplankton fraction, i.e. planktonic groups whose linear size is less than $3 \mu \mathrm{m}$. This fraction is formed by groups belonging to two different domains, i.e. picoprokayotes and picoeukaryotes (Olson et al., 1993; Casotti et al., 2003; Brunet et al., 2008), and takes in account, on average, about $80 \%$ of the total chlorophyll a (chl a) and divinyl chlorophyll a (Dvchl a) in Mediterranean Sea.

The spatio-temporal dynamics of phytoplankton populations, including their competition for light and nutrient, is modeled by using three different systems of coupled differential equations. As a first step, a stochastic advection-reaction-diffusion model is used to reproduce the vertical distributions of one picophytoplankton group, i.e. the picoeukaryotes domain. This study is performed in a hydrologically stable site of the Sicily Channel during the summer season, when the best life conditions are guaranteed for the population investigated. The second model, which is an extended version of the first one, is used to obtain the vertical stationary profiles of two groups of picophytoplankton, i.e. Pelagophytes and Prochlorococcus. Here, the stochastic model includes interspecific competition between the two picophytoplanktonic groups for limiting factors. As a third step, we analyze the spatio-temporal behaviour of five picophytoplankton populations in a site of the Tyrrhenian Sea by using a stochastic reaction-diffusion-taxis model. In this case, the study is performed by taking into account the seasonal variations of environmental variables, obtained starting from field observations.

In all three cases studied, in order to compare theoretical results with experimental findings, the picophytoplankton cell concentrations obtained by the model and expressed in cells $/ \mathrm{m}^{3}$ are converted in chl $a$ and Dvchl $a$ concentrations, expressed in $\mu \mathrm{g} / \mathrm{dm}^{3}$, by using the experimental cellular content measured by Morel and the conversion curves obtained by Brunet et al. (Morel, 1997; Brunet et al., 2007). The agreement between theoretical chlorophyll distributions and corresponding experimental profiles, for different noise intensities, is evaluated by using two comparative methods based on the $\chi^{2}$ goodness-of-fit and KolmogorovSmirnov (K-S) tests.

\section{Materials and methods}

\subsection{Environmental data}

The experimental data analyzed in this work were collected in the period 22nd August 2006-9th June 2007 in two sampling sites located in the middle of the Mediterranean Sea (see Fig. 1). These sites represent two hydrologically stable areas, where oligotrophic waters are mainly populated by picophytoplankton groups during the whole year. The experimental findings used in the first two cases analyzed in this work (one-population and two-population models) were acquired in the site $\left(35^{\circ} 18.17^{\prime} \mathrm{N}, 13^{\circ} 44.44^{\prime} \mathrm{E}\right)$, localized in the Strait of Sicily, during the MedSudMed-06
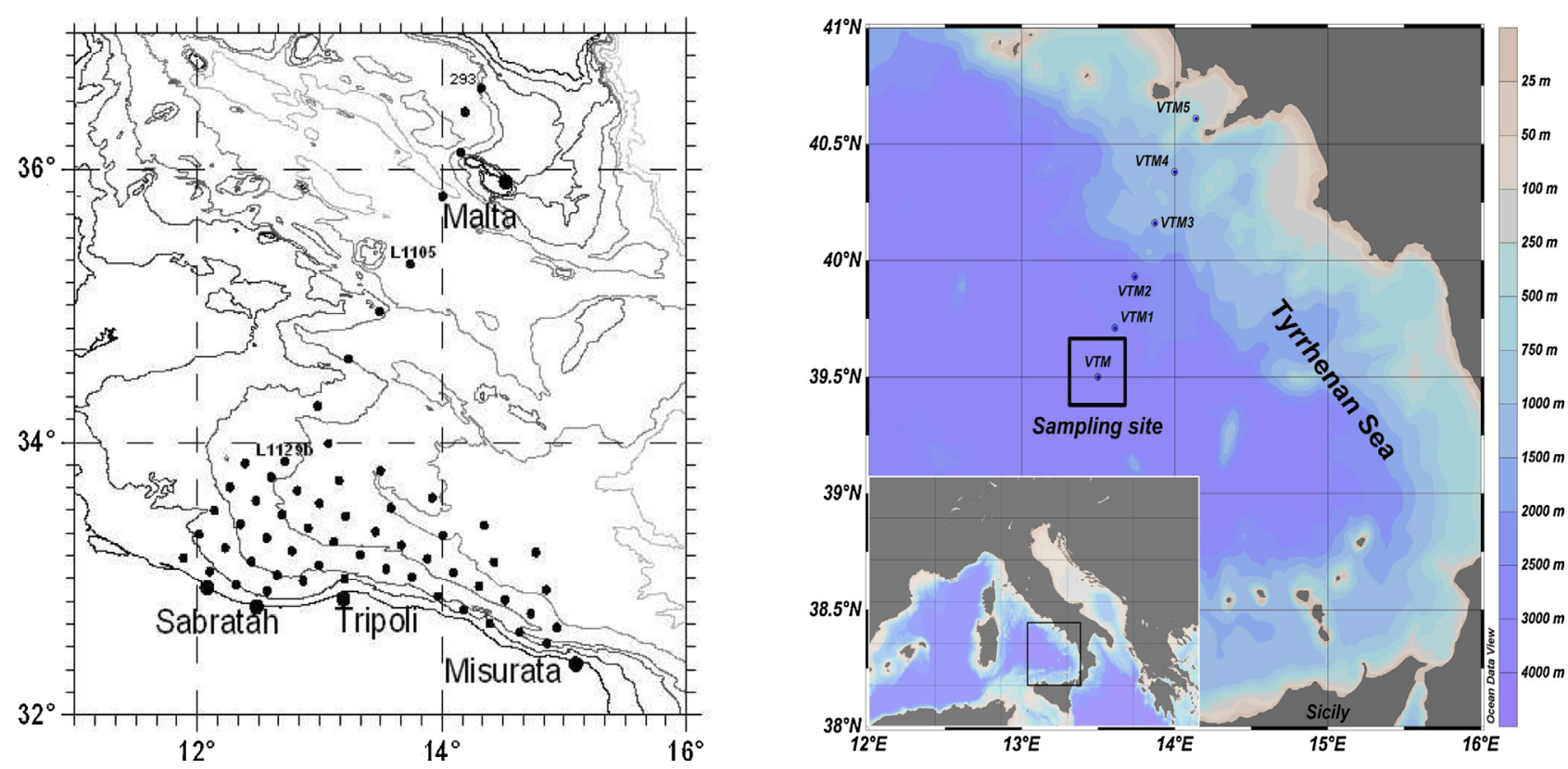

Fig. 1. Location of the two sampling sites where the experimental data were collected.

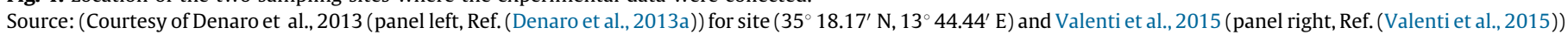
for site $\left(39^{\circ} 30.00^{\prime} \mathrm{N}, 13^{\circ} 30.00^{\prime} \mathrm{E}\right)$.) 
Oceanographic Survey performed in August 2006 on board the R/V Urania (Gasparini et al., 2008; Bonanno et al., 2013). The field observations used in the third case (five-population model) were collected in the period from 24th November 2006 to 9th June 2007 in a sampling site $\left(39^{\circ} 30.00^{\prime} \mathrm{N}, 13^{\circ} 30.00^{\prime} \mathrm{E}\right)$ localized in the middle of the Tyrrhenian Sea. Here, the seasonal variability of physical parameters and chlorophyll concentrations was investigated by using the experimental data acquired at four different times of the year, during four different oceanographic cruises (VECTOR-TM1, November 2006; VECTOR-TM2, February 2007; VECTOR-TM3, April 2007; VECTOR-TM4, June 2007) performed on board the R/V Urania. Moreover, an accurate estimate of vertical turbulent diffusivity for the whole year was obtained by taking into account the vertical profiles of physical parameters collected during other three oceanographic cruises (VECTOR-TM6, January 2009; VENUS1, August 2010; TYR01, October 2010).

In general, during the sampling periods investigated environmental conditions remained constant. Therefore, in all oceanographic surveys similar sampling strategies and methodologies were used. In particular, vertical profiles of temperature, salinity and density were acquired by using a CTD probe equipped with a fluorescence sensor, which measured total chlorophyll concentrations. Moreover, nitrate, nitrite, silicate and phosphate concentrations, were collected in polyethylene vials and stored at $-20{ }^{\circ} \mathrm{C}$ during all cruises except the MedSudMed-06 Oceanographic Survey. Finally, the nutrient concentrations were obtained by using classical methods of measurement (Ribera d'Alcalà et al., 2009; La Ferla et al., 2012; Grasshoff, 1976).

\subsection{Phytoplanktonic data}

The contribution of each phytoplankton population to the total amount of chlorophyll is based on: (i) the experimental estimation of cellular chlorophyll a content (Morel, 1997; Brunet et al., 2006, 2007) obtained by performing the high-performance liquid chromatography (HPLC) analysis on the bottle samples collected in the sites investigated; (ii) the theoretical abundance obtained from the stochastic models (Denaro et al., 2013a,b).

In this paragraph, we study the composition of the phytoplankton community, which can be divided into three main size fractions (Casotti et al., 2003, 2000): pico- $(<3 \mu \mathrm{m})$, nano- (3$20 \mu \mathrm{m})$ and micro-phytoplankton $(>20 \mu \mathrm{m})$. Specifically, in the marine ecosystems investigated (Mediterranean Sea), the picophytoplankton fraction amounts in average to about $80 \%$ of the total chl $a$ and Dvchl $a$, and is dominated by two groups: picoprokaryotes and picoeukaryotes. The picoprokaryotes domain is composed of two genera of cyanobacteria, i.e. Synechococcus and Prochlorococcus, while picoeukaryotes domain is mainly represented by Haptophytes and Pelagophytes (Garczarek et al., 2007; Mella-Flores et al., 2011; La Ferla et al., 2012). The nano- and micro-phytoplankton fraction accounts for about $20 \%$ of the total chl $a$ and Dvchl $a$ on average, and is mainly represented by Haptophytes, Pelagophytes and diatoms. This fraction is poorly present in DCM, and is almost uniformly distributed along the water column.

In our study, we reproduce the spatio-temporal dynamics of five picophytoplankton populations, which are located at different depths along the water column. In particular, close to the water surface a prevalence of Synechococcus on the other groups is observed, with Prochlorococcus concentration remaining constant with depth. Conversely, Prochlorococcus prevails numerically respect to other groups in intermediate layers (Brunet et al., 2007), where the coexistence of two ecotypes of this genus is observed: high light-adapted (HL-) ecotype and low light-adapted (LL-) ecotype. The heterogenous composition is also a feature of the picoeukaryotes domain in Mediterranean Sea. Indeed, Brunet et al. have found that haptophytes are more abundant in shallower layers of DCM, while Pelagophytes prevail in deeper layers (Brunet et al., 2006, 2007).

The analysis of bottle samples show that Synechococcus contributes to more than $20 \%$ of the total chlorophyll concentration on average in the Mediterranean Sea (Brunet et al., 2006, 2007). However, the chl a cellular content of Synechococcus is not estimated. Therefore, in our study, we chose to use the content measured by Morel in Mauritania coast, whose value was fixed equal to $2 \mathrm{fg}$ chl $a$ cell $^{-1}$ (Morel, 1997).

In both sites investigated, Prochlorococcus and picoeukaryotes dominate deeper layers and contribute equally to the picophytoplankton biomass in terms of chl $a$ and Dvchl a concentrations in DCM. Specifically, the bottle samples collected in Mediterranean Sea showed that the cellular content of chl $a$ and Dvchl $a$ increases in picoeukaryotes and Prochlorococcus with decreasing light conditions (Brunet et al., 2007; Moore et al., 1995). Indeed, the Dvchl a cellular content of the total Prochlorococcus, including both ecotypes, ranges between 0.25 and $2.20 \mathrm{fg}$ Dvchl $a$ cell $^{-1}$ along the water column, with a mean value exponentially increasing with depth (Brunet et al., 2007). On the other side, the mean chl a cellular content of the picoeukaryotes ranges between $10 \mathrm{fg} \mathrm{chl} \mathrm{a} \mathrm{cell}^{-1}$ in sea surface and $660 \mathrm{fg} \mathrm{chl} \mathrm{a} \mathrm{cell}^{-1}$ in deeper layers (Brunet et al., 2007). This conversion curve has been used to estimate chl a concentrations due to the presence of all picoeukaryotes groups studied.

The vertical profiles of chl a concentration, acquired in two sites analyzed, show a nonmonotonic behaviour characterized by the presence of a deep chlorophyll maximum (DCM). The analysis performed in sampling site $\left(39^{\circ} 30.00^{\prime} \mathrm{N}, 13^{\circ} 30.00^{\prime} \mathrm{E}\right)$ localized in Tyrrhenian Sea, indicates that depth, shape and width of DCM change as a function of the time. In particular, we observe that the chl a concentration in DCM reaches the maximum value in summer season. In this period, in fact, a limited mixing causes a decrease of nutrient concentration in the DCM due to a strong stratification of the water masses between late spring and early fall. Moreover, an increase of the width of the DCM is observed in late fall and winter, when the vertical turbulent diffusivity increases along the whole water column (Valenti et al., 2015).

In both sites investigated, the field observations show that the chl a concentrations assume almost uniform values in the upper mixed layer (UML). Here, the average chl a concentration changes during the year, showing a maximum value in February. This behaviour is strictly connected with the seasonal variations of the vertical turbulent diffusivity, which reaches a maximum in the UML during the winter season, taking on low values in other periods of the year (Valenti et al., 2015).

\section{One-population model}

In this section we present a study on the spatio-temporal behaviour of the picoeukaryotes domain, exploiting a stochastic one-population model. The analysis is performed comparing theoretical results with experimental data sampled in the site $\left(35^{\circ} 18.17^{\prime} \mathrm{N}, 13^{\circ} 44.44^{\prime} \mathrm{E}\right)$, located in the Strait of Sicily, where the water columns are weakly mixed during the summer season and the presence of DCM is guaranteed by the vertical profiles of limiting factors, i.e. light intensity and phosphorous concentration.

In the last years, the dynamics of a single phytoplankton group in marine ecosystems has been investigated in a series of theoretical works exploiting deterministic models (Shigesada and Okubo, 1981; Klausmeier and Litchman, 2001; Huisman et al., 2002; Ryabov and Blausius, 2008; Valenti et al., 2012; Denaro et al., 2013a). In general, the mathematical approach used to describe the phytoplankton dynamics is based on an archetypal tool, known as advection-reaction-diffusion model (Shigesada and Okubo, 1981; Huisman et al., 2002; Ryabov and Blausius, 2008; 
Valenti et al., 2012; Denaro et al., 2013a). Specifically, the first theoretical studies performed on the phytoplankton dynamics (Shigesada and Okubo, 1981; Huisman et al., 2002) considered only one limiting factor, i.e. light intensity, without taking into account the heterogenous distribution of the nutrients, such as nitrogen and phosphorous, along the water column. Afterwards, in more recent works, some authors modified the reaction term of the model to reproduce the effects of two limiting factors on phytoplankton dynamics (Klausmeier and Litchman, 2001; Ryabov and Blausius, 2008; Valenti et al., 2012; Denaro et al., 2013a) by using the Monod kinetics for both light intensity and nutrient concentration. Moreover, in order to consider the effects of the active movement of some phytoplankton populations on the vertical biomass distributions, Klausmeier and Litchman changed the deterministic model by replacing the advection term with a taxis term (Klausmeier and Litchman, 2001).

However, all these analyses miss to describe the overall interaction between phytoplankton populations and environment. Indeed, natural systems are affected not only by deterministic forces but also random perturbations coming from the environment. In this context environmental variables, due to their random fluctuations, can act as noise sources, causing phytoplankton to be subject to a stochastic dynamics (Valenti et al., 2012; Denaro et al., 2013a). Therefore, in order to describe the real dynamics of the phytoplankton population considered in this section, we exploit a new theoretical model consisting of stochastic differential equations. Finally, we remark the second novelty introduced in this study: the comparison between theoretical and experimental distributions of chlorophyll concentration performed by using a statistical test. Indeed, in order to validate the numerical results obtained by the model, the theoretical cell concentrations of picoeukaryotes are converted into chl a concentrations, and compared with experimental chlorophyll profiles. The lack of any quantitative validation in previous works can be explained, to some extent, recalling that the first conversion curves have been obtained in 2006, performing HPLC analysis on bottle samples collected in Mediterranean Sea (Brunet et al., 2006, 2007).

\subsection{The stochastic one-population model}

In this paragraph we analyze the spatio-temporal dynamics of a picoeukaryotes population by using a stochastic advectionreaction-diffusion model (Valenti et al., 2012; Denaro et al., 2013a) distributed along a one-dimensional spatial domain ( $z$ direction). The model consists of two stochastic partial derivative equations (Valenti et al., 2012; Denaro et al., 2013a) and an auxiliary equation, and allow to obtain the dynamics of the picoeukaryotes abundance $b(z, t)$, nutrient concentration $R(z, t)$, and light intensity $I(z, t)$ along a water column, at different depth, during the time. The spatio-temporal behaviour of the picoeukaryotes abundance is the result of three processes: growth, loss, and movement. It is important to recall that the phytoplankton growth rate depends on $R(z, t)$ and $I(z, t)$ (Klausmeier and Litchman, 2001; Klausmeier et al., 2007; Mei et al., 2009; Bougaran et al., 2010; Ryabov et al., 2010), while its specific loss rate $m$ is connected with respiration, death, and grazing (Klausmeier and Litchman, 2001; Huisman et al., 2006; Ryabov et al., 2010; Denaro et al., 2013a). The passive movement of the picoeukaryotes is modeled by using a diffusion term, which mimics the effects of turbulence in the marine site investigated. Moreover, here we assume that the vertical turbulent diffusivity is uniform with the depth and characterized by a low value $\left(D=0.5 \mathrm{~cm}^{2} \mathrm{~s}^{-1}\right)$, in agreement with the values estimated in the Strait of Sicily during the summer season. In order to reproduce the sinking of the planktonic population along the water column, we inserted an advection term in the differential equation that describes the picoeukaryotes dynamics.
To take into account random fluctuations we insert a term of spatially uncorrelated noise in the equation for the nutrient dynamics. In particular, we use a source of multiplicative noise $\xi_{R}(z, t)$ with intensity $\sigma_{R}$ and statistical properties given by $\left\langle\xi_{R}(z\right.$, $t)\rangle=0$ and $\left\langle\xi_{R}(z, t) \xi_{R}\left(z^{\prime}, t^{\prime}\right)\right\rangle=\sigma_{R} \delta\left(z-z^{\prime}\right) \delta\left(t-t^{\prime}\right)$. Finally, the light intensity $I(z, t)$ is modeled by the Lambert-Beer's law, which is a function varying, along the water column, with the depth $z$ and picoeukaryotes cell concentration $b(z, t)$. The stochastic model is defined by the following equations:

$$
\begin{aligned}
& \frac{\partial b(z, t)}{\partial t}= b \min \left(f_{I}(I), f_{R}(R)\right)-m b+D \frac{\partial^{2} b(z, t)}{\partial z^{2}}-v \frac{\partial b(z, t)}{\partial z} \\
& \frac{\partial R(z, t)}{\partial t}=-\frac{b(z, t)}{Y} \cdot \min \left(f_{I}(I), f_{R}(R)\right)+D \frac{\partial^{2} R(z, t)}{\partial z^{2}} \\
&+\sum \varepsilon m \frac{b(z, t)}{Y}+R \xi_{R}(z, t) \\
& I(z, t)=I_{\text {in }} \exp \left\{-\int_{0}^{z}\left[a b(Z, t)+a_{b g}\right] d Z\right\}
\end{aligned}
$$

where $v$ is the sinking velocity of the picoeukaryotes; $D$ is the vertical turbulent diffusivity; $\varepsilon, m$ and $1 / Y$ are nutrient recycling coefficient, specific loss rate and nutrient content of the picoeukaryotes, respectively; $a$ is the absorption coefficient of the picoeukaryotes, and $a_{b g}$ is the background turbidity; $I_{i n}$ is the incident light intensity at the water surface. Finally, $f_{I}(I)$ and $f_{R}(R)$ are given by the Michaelis-Menten formulas

$$
\begin{aligned}
& f_{I}(I)=r I /\left(I+K_{I}\right), \\
& f_{R}(R)=r R /\left(R+K_{R}\right) .
\end{aligned}
$$

Here $r$ is the maximum growth rate, $K_{I}$ and $K_{R}$ are the halfsaturation constants for light intensity and nutrient concentration, respectively, of the picoeukaryotes. The stochastic model also includes four equations for the boundary conditions. In particular, picoeukaryotes cells does not enter or leave the water column. Therefore, the boundary conditions

$\left.\left[D \frac{\partial b}{\partial z}-v b\right]\right|_{z=0}=\left.\left[D \frac{\partial b}{\partial z}-v b\right]\right|_{z=z_{b}}=0$

for picoeukaryotes abundance account for the absence of flux through both surface layer $z=0$ and seabed $z=z_{b}$.

Moreover, we fix the boundary conditions for nutrients, which do not come from the top of the water column but are provided from the seabed. Here, the phosphorus concentration is set to the constant value $R_{\text {in }}$ and, as a consequence, to the value $R\left(z_{b}\right)$ in the bottom of the water column. Indeed, the phosphorus diffuses across the sediment-water interface with a rate proportional to the concentration difference between the solid phase (seabed) and the deepest water layer (bottom of the water column). Therefore, the boundary conditions for phosphorus concentration are given by

$\left.\frac{\partial R}{\partial z}\right|_{z=0}=0,\left.\quad \frac{\partial R}{\partial z}\right|_{z=z_{b}}=h\left(R_{i n}-R\left(z_{b}\right)\right)$,

where $h$ is the permeability of the interface. Eqs. (1)-(7) form the stochastic advection-reaction-diffusion model used in this study. By solving them we obtain the spatio-temporal behaviour of the picoeukaryotes abundance, nutrient concentration and light intensity.

\subsection{Results of the stochastic one-population model}

The theoretical distributions of cell concentration for picoeukaryotes is obtained by solving numerically Eqs. (1)-(7) within the Ito scheme, and averaging over 1000 realizations (Spagnolo et al., 2004; 
Table 1

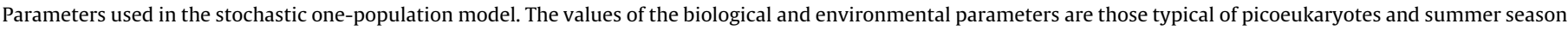
in the Strait of Sicily, respectively.

\begin{tabular}{|c|c|c|c|}
\hline Symbol & Interpretation & Units & Value \\
\hline$a_{b g}$ & Background turbidity & $\mathrm{m}^{-1}$ & 0.045 \\
\hline$a$ & Absorption coefficient of picoeukaryotes & $\mathrm{m}^{2}$ cell $^{-1}$ & $6 \times 10^{-10}$ \\
\hline$r$ & Maximum specific growth rate of picoeukaryotes & $\mathrm{h}^{-1}$ & 0.08 \\
\hline$K_{I}$ & Half-saturation constant of light-limited growth of picoeukaryotes & $\mu \mathrm{mol}$ photons $\mathrm{m}^{-2} \mathrm{~s}^{-1}$ & 20 \\
\hline$K_{R}$ & Half-saturation constant of nutrient-limited growth of picoeukaryotes & mmol nutrient $\mathrm{m}^{-3}$ & 0.0425 \\
\hline$m$ & Specific loss rate of picoeukaryotes & $\mathrm{h}^{-1}$ & 0.01 \\
\hline $1 / Y$ & Nutrient content of picoeukaryotes & mmol nutrient cell ${ }^{-1}$ & $1 \times 10^{-9}$ \\
\hline$\epsilon$ & Nutrient recycling coefficient & dimensionless & 0.5 \\
\hline$v$ & Sinking velocity of picoeukaryotes & $\mathrm{m} \mathrm{h}^{-1}$ & 0.0042 \\
\hline$c$ & Chl-a cellular content of picoeukaryotes (as a function of depth) & fg chl-a cell ${ }^{-1}$ & $10.0-660.0$ \\
\hline$D$ & Vertical turbulent diffusivity & $\mathrm{cm}^{2} \mathrm{~s}^{-1}$ & 0.5 \\
\hline$h$ & Sediment-water column permeability & $\mathrm{m}^{-1}$ & 0.01 \\
\hline$I_{\text {in }}$ & Incident light intensity & $\mu \mathrm{mol}$ photons $\mathrm{m}^{-2} \mathrm{~s}^{-1}$ & 1383.19 \\
\hline$R_{\text {in }}$ & Nutrient concentration at $z_{b}$ & mmol nutrient $\mathrm{m}^{-3}$ & 36.0 \\
\hline$z_{b}$ & Depth of the water column & $\mathrm{m}$ & 575 \\
\hline
\end{tabular}

Giuffrida et al., 2009; Denaro et al., 2013a,b). The numerical method, whose computer implementation consists in a C++ program, is based on an explicit finite difference scheme with centered-in-space differencing for the diffusion term and forward differencing for the advection term. The increment of the spatial variable and the time step are set at $0.5 \mathrm{~m}$ and $0.05 \mathrm{~h}$, respectively. These values are chosen such as to respect the von Neumann's stability conditions for both differencing terms (Roache, 1976, 1998; Tveito and Winther, 1998).

In view of reproducing the vertical profiles of chl a concentration observed in the experimental findings, we fixed the values of the environmental and biological parameters to satisfy the monostability condition corresponding to the presence of a deep chlorophyll maximum (Ryabov et al., 2010). The numerical values assigned to the parameters are shown in Table 1 .

In particular, the biological parameters $\left(r, K_{I}, K_{R}\right.$ and $\left.v\right)$ have been chosen to reproduce the behaviour of picoeukaryotes, while the environmental parameters are set on the basis of the data coming from the remote sensing ( see NASA web site ${ }^{1}$ ) and field observations.

In order to get the steady spatial distributions of picoeukaryotes abundance, we integrate our equations system over a time interval long enough to obtain the stationary solution (Valenti et al., 2012; Denaro et al., 2013a). Because a preliminary analysis performed by deterministic approach showed that the stationary state is reached at $t \approx 3 \times 10^{4} \mathrm{~h}$, we solve the equations of the stochastic model by using a maximum time $t_{\max }=4 \times 10^{4} \mathrm{~h}$.

As initial condition for the biomass, we consider the picoeukaryotes abundance concentrated in the layer in which the maximum of the experimental chlorophyll distribution is observed. Concerning the initial nutrient concentration, this is set at a constant value from the water surface to the DCM, and increases linearly below this point up to the seabed.

Moreover we perform a quantitative validation based on a statistical test which allows to measure the agreement between experimental and theoretical chlorophyll concentrations. At this aim, in order to compare theoretical distributions with experimental chlorophyll profiles, the theoretical cell concentrations of picoeukaryotes are converted into chl a concentrations, by using the curve of mean vertical profile obtained by Brunet et al. (2007).

We recall that about $43 \%$ of the total quantity of chl $a$ and divinil chl a (Huisman et al., 2006; Brunet et al., 2006) present in the Strait of Sicily is due to nano- and micro-phytoplankton, and Synechococcus. Therefore, we consider this fraction of the total chlorophyll and divide it by depth, obtaining for each site the value $\Delta b_{(D v) c h l a}$, which represents a constant concentration of chl $a$ and $D V c h l a$ due to other phytoplankton groups present in the water column. Finally, we sum the theoretical chl a concentrations with

\footnotetext{
${ }^{1}$ http://eosweb.larc.nasa.gov/sse/RETScreen/.
}

$\Delta b_{(D v) c h l a}$. By this way, we obtain the stationary distributions in deterministic conditions and for five different values of the noise intensity. The results are shown in Fig. 2. Here, we can observe that a decrease of chl a concentration and a deeper localization of the DCM are present also for low noise intensities $\left(\sigma_{R}\right.$ between 0.001 and 0.010). The shape of the theoretical profiles of chl $a$ concentration exhibits, for the site studied, a better agreement with the corresponding experimental DCM respect to the deterministic case $\left(\sigma_{R}=0\right)$. In particular, the best value of the $\chi^{2}$ test is obtained for $\sigma_{R}=0.0015$ (see Table 2).

To better understand the dependence of the chl a concentration on the stochastic dynamics of the phosphorus concentration, we study the theoretical behaviour of the depth, width, and magnitude of the DCM as a function of $\sigma_{R}$ (see Fig. 3). The numerical results show that a rapid decrease of the chl a concentration in the DCM is obtained, when the random fluctuations of environmental variables increase (see panel a of Fig. 3). Indeed, the chl a concentration takes on low values in the DCM $(\sim 0.025)$ in correspondence of higher noise intensities $\left(\sigma_{R} \sim 0.01\right)$. Moreover, we note that the depth of the DCM slightly increases with the environmental noise. Analogously, a rapid increase of the width of the DCM is observed as a function of the noise intensity (see panel c of Fig. 3).

In general, the spread of DCM and reduction of its magnitude are strictly connected with each other. Indeed, the decrease of chl a concentration causes a flattening of the DCM with a consequent increase of its width, which leads to a disappearance of picoeukaryotes for $\sigma_{R} \sim 0.01$.

In conclusion, the random fluctuations of environmental variables can modify strongly the spatio-temporal behaviour of nutrient concentration, causing dramatic effects up to the extinction of population.

\section{Two-population model}

The results of the statistical checks, carried out in the previous paragraph, show that the stochastic one-population model is not able to well reproduce the experimental chlorophyll profiles. For this reason, some authors extended the deterministic onepopulation model in order to consider the two phytoplankton populations which give the major contribution to the total chlorophyll concentration in marine ecosystems (Ryabov et al., 2010; Ryabov and Blasius, 2011; Ryabov, 2012; Denaro et al., 2013b,c; Denaro, 2014). In particular, in recent works, Ryabov et al. investigated the influence of environmental parameters on the resource competition between two phytoplankton groups in heterogenous aquatic ecosystems (Ryabov et al., 2010; Ryabov and Blasius, 2011; Ryabov, 2012). More specifically, these authors established that the coexistence of two phytoplankton populations 

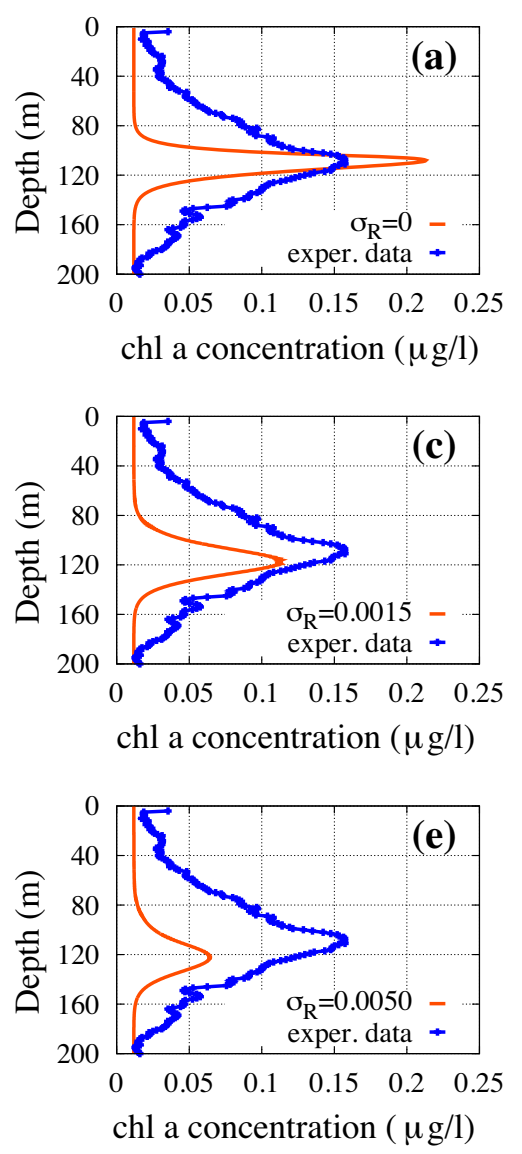
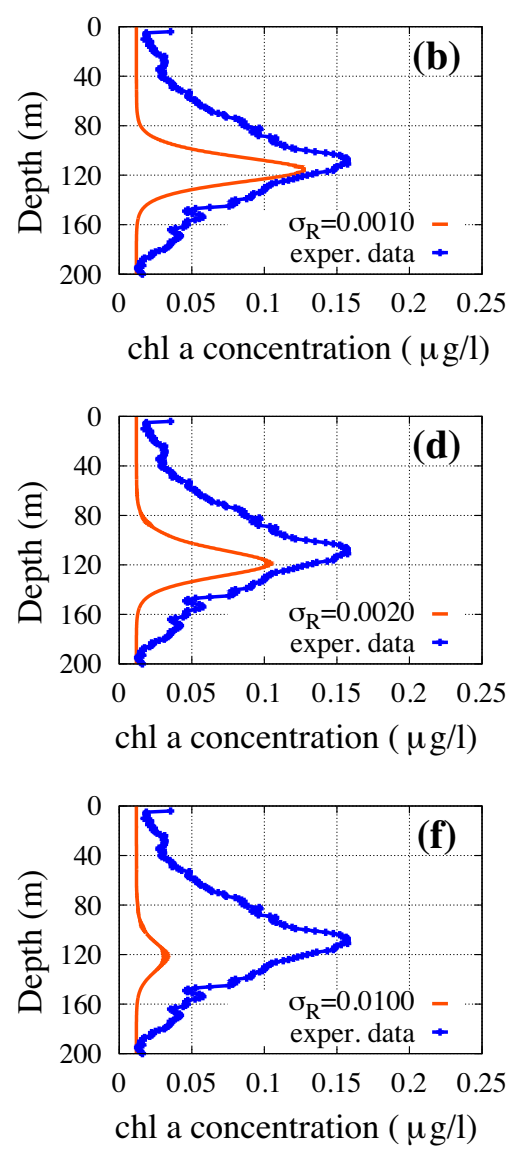

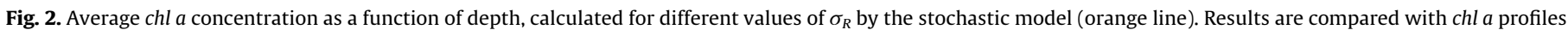

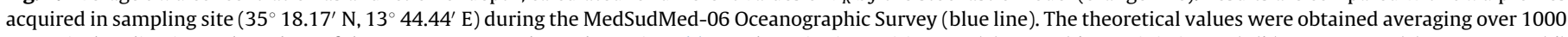

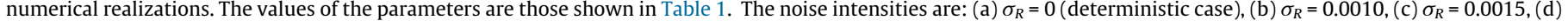

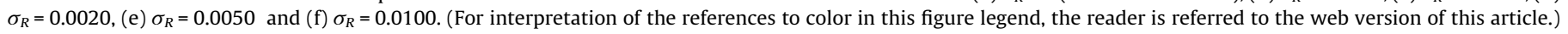

along the water column depends on the vertical profiles of both the limiting factors, i.e. light intensity and nutrient concentration, and the physical variables, such as vertical turbulent diffusivity (Ryabov et al., 2010; Ryabov and Blasius, 2011; Ryabov, 2012). However, in the Ryabov's works, no comparison between theoretical results and experimental data, collected in real aquatic ecosystems, has been performed. This can be explained not only by the difficulties of obtaining experimental chlorophyll profiles, but also due to the lack of conversion curves, two elements which represent important novelties of our analyses.

In order to improve the results of the $\chi^{2}$ test of the previous section, here the spatio-temporal behaviour of two picophytoplankton groups is reproduced by using an extension of the stochastic onepopulation model. Aim of this analysis is obtaining with a higher accuracy the chl a concentrations experimentally observed, taking into account another phytoplanktonic group, which contributes in a

Table 2

Results of $\chi^{2}$ and reduced chi-square $\left(\tilde{\chi}^{2}\right)$ goodness-of-fit

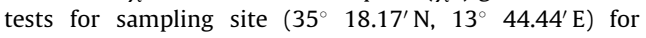
different values of $\sigma_{R}$. The number of samples, used for the tests and distanced of $1 \mathrm{~m}$, is $n=200$ corresponding to consider from the surface the first $200 \mathrm{~m}$ of depth.

\begin{tabular}{lll}
\hline$\sigma_{R}$ & $\chi^{2}$ & $\tilde{\chi}^{2}$ \\
\hline 0.0000 & 22.87 & 0.0407 \\
0.0010 & 17.49 & 0.0888 \\
0.0015 & 17.37 & 0.0882 \\
0.0020 & 17.87 & 0.0907 \\
0.0050 & 24.97 & 0.1268 \\
0.0100 & 40.62 & 0.2062 \\
\hline
\end{tabular}

significative way to the total concentration of chl $a$. The analysis is therefore performed considering the following populations: (i) Pelagophytes, which belongs to the picoeukaryotes domain; (ii) Prochlorococcus, which is a genus belonging to the picoprokaryotes domain. These communities account about for $60 \%$ of the total chlorophyll a on average in the Mediterranean Sea.

By following the same procedure as in Section 3, we reproduce the vertical profiles of chl a concentration acquired in the same sampling site as in the previous section.

\subsection{The stochastic two-population model}

In this paragraph we analyze the spatio-temporal behaviour of the two picophytoplanktonic groups (Denaro et al., 2013b,c) by using a stochastic model, which enables to reproduce the dynamics of the cell concentrations of Pelagophytes and Prochlorococcus, $b_{1}(z, t)$ and $b_{2}(z, t)$, nutrient concentration $R(z, t)$ and light intensity $I(z, t)$. Unlike other works on the two-population models (Ryabov et al., 2010; Ryabov and Blasius, 2011; Ryabov, 2012; Denaro et al., 2013c), here we introduce a further novelty which allows to take into account the effects of environmental noise on the dynamics of nutrient, Pelagophytes and Prochlorococcus, simultaneously. In particular, the environmental random fluctuations are considered inserting terms of spatially uncorrelated noise in the differential equations. More specifically, we use three sources of multiplicative noise $\xi_{b_{1}}(z, t), \xi_{b_{2}}(z, t)$ and $\xi_{R}(z, t)$ with the following statistical properties: $\quad\left\langle\xi_{b_{i}}(z, t)\right\rangle=0, \quad\left\langle\xi_{R}(z, \quad t)\right\rangle=0, \quad\left\langle\xi_{b_{i}}(z, t) \xi_{b_{i}}\left(z^{\prime}, t^{\prime}\right)\right\rangle$ $=\sigma_{b_{i}} \delta\left(z-z^{\prime}\right) \delta\left(t-t^{\prime}\right),\left\langle\xi_{R}(z, t) \xi_{R}\left(z^{\prime}, t^{\prime}\right)\right\rangle=\sigma_{R} \delta\left(z-z^{\prime}\right) \delta\left(t-t^{\prime}\right)$, with $i=1,2$. Here, $\sigma_{b_{i}}$ and $\sigma_{R}$ are the intensities of the noise sources 
chl a concentration in DCM

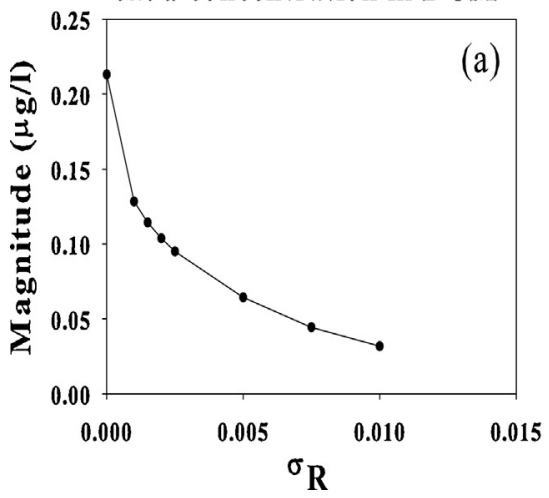

Depth of DCM

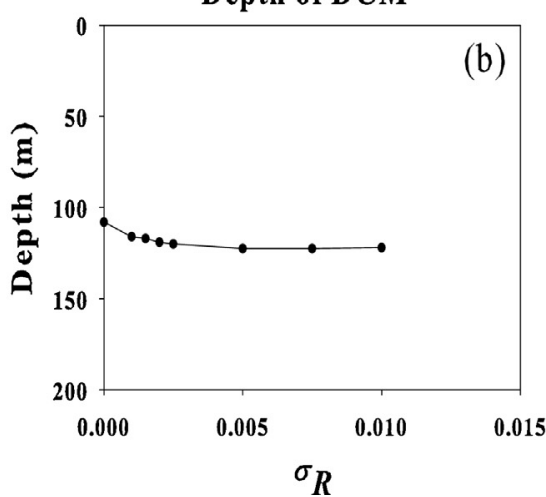

Width of DCM

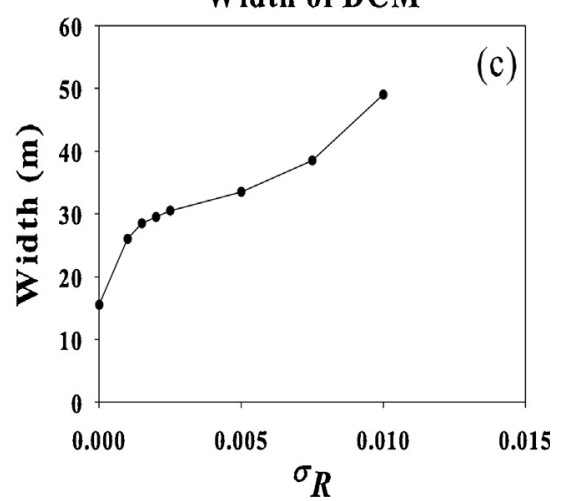

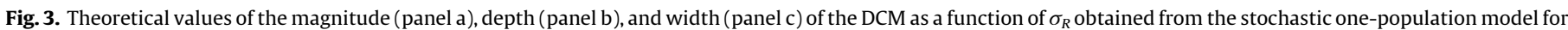
sampling site $\left(35^{\circ} 18.17^{\prime} \mathrm{N}, 13^{\circ} 44.44^{\prime} \mathrm{E}\right)$. The values shown have been calculated at the steady state.

which act on the $i$-th picophytoplanktonic group and nutrient, respectively.

The light intensity $I(z, t)$ decreases exponentially according to the Lambert-Beer's law, which is a function varying with the depth $z$ and the abundance $b_{1}(z, t)$ and $b_{2}(z, t)$ of the two phytoplanktonic groups. The stochastic two-population model is therefore defined by the following equations

$$
\begin{aligned}
\frac{\partial b_{1}(z, t)}{\partial t} & =b_{1} \min \left(f_{I_{1}}(I), f_{R_{1}}(R)\right)-m_{1} b_{1}+D \frac{\partial^{2} b_{1}(z, t)}{\partial z^{2}}-v_{1} \frac{\partial b_{1}(z, t)}{\partial z} \\
& +b_{1} \xi_{b_{1}}(z, t)
\end{aligned}
$$

$$
\begin{aligned}
\frac{\partial b_{2}(z, t)}{\partial t} & =b_{2} \min \left(f_{I_{2}}(I), f_{R_{2}}(R)\right)-m_{2} b_{2}+D \frac{\partial^{2} b_{2}(z, t)}{\partial z^{2}}-v_{2} \frac{\partial b_{2}(z, t)}{\partial z} \\
& +b_{2} \xi_{b_{2}}(z, t)
\end{aligned}
$$

$$
\begin{aligned}
\frac{\partial R(z, t)}{\partial t} & =-\sum \frac{b_{i}(z, t)}{Y_{i}} \cdot \min \left(f_{I_{i}}(I), f_{R_{i}}(R)\right)+D \frac{\partial^{2} R(z, t)}{\partial z^{2}} \\
& +\sum \varepsilon_{i} m_{i} \frac{b_{i}(z, t)}{Y_{i}}+R \xi_{R}(z, t)
\end{aligned}
$$

$I(z, t)=I_{i n} \exp \left\{-\int_{0}^{z}\left[\sum a_{i} b_{i}(Z, t)+a_{b g}\right] d Z\right\}$,

where $v_{1}$ and $v_{2}$ are the sinking velocities of the two picophytoplankton groups i.e. Pelagophytes and Prochlorococcus, respectively; $D$ is the vertical turbulent diffusivity; $\varepsilon_{i}, m_{i}$, and $1 / Y_{i}$ are nutrient recycling coefficient, specific loss rate and nutrient content of the $i$-th picophytoplankton group, respectively; $a_{1}$ and $a_{2}$ are the absorption coefficients of the two picophytoplankton groups, and $a_{b g}$ is the background turbidity; $I_{i n}$ is the incident light intensity at the water surface. Finally, $f_{I_{i}}(I)$ and $f_{R_{i}}(R)$ are given by the Michaelis-Menten formulas for both picophytoplankton groups (see Eqs. (4) and (5)).

The boundary conditions have to describe the absence of biomass flux through both surface layer $z=0$ and seabed $z=z_{b}$ :

$\left.\left[D \frac{\partial b_{i}}{\partial z}-v_{i} b_{i}\right]\right|_{z=0}=\left.\left[D \frac{\partial b_{i}}{\partial z}-v_{i} b_{i}\right]\right|_{z=z_{b}}=0$.

For the nutrient we give boundary conditions partially different respect to those used in Section 3. In particular, the first condition remains unaltered (no nutrient flux from the water surface), while the second condition changes. Indeed, phosphorus (nutrient) concentration at the bottom of the water column, $z=z_{b}$, is set at the value $R_{i n}$. This choice leads to a more precise estimate of the real value of $R$ in the deepest layer, providing the value of the nutrient solved in the water instead of the value in the seabed. Moreover, this setting allows to restrict the study to the euphotic zone of the water column, which corresponds approximately to the Modified Atlantic Water (MAW), i.e. the upper layer of the Mediterranean basin. As a result, the boundary conditions for the nutrient concentration are given by

$\left.\frac{\partial R}{\partial z}\right|_{z=0}=0, \quad R\left(z_{b}\right)=R_{\text {in }}$.

Eqs. (8)-(13) form the stochastic advection-reaction-diffusion model for the two-population system.

\subsection{Results of the stochastic two-population model}

We integrate Eqs. (8)-(13) by the same numerical methods as in Subsection 3.2. In particular, we obtain the cell concentration profiles. Moreover, the increment of the spatial variable $(0.5 \mathrm{~m})$ and the time step $(0.05 \mathrm{~h})$ are set such as to respect the stability conditions for both differencing terms (Roache, 1976, 1998; Tveito and Winther, 1998).

To obtain the vertical profiles of the total chl a concentration, we set the values of the environmental and biological parameters so that the presence of a deep chlorophyll maximum for both picophytoplankton groups is guaranteed (Huisman et al., 2006; Ryabov et al., 2010; Ryabov, 2012; Denaro et al., 2013b,c). In particular, the half-saturation constants and the nutrient contents for each group are chosen to get suitable positions of the production layers and appropriate magnitudes of the cell concentration, respectively. Conversely, the other biological parameters are set to values typical of the picophytoplankton, in agreement with those experimentally observed by other authors (Bertilsson et al., 2003; Timmermans et al., 2005; Veldhuis et al., 2005; Huisman et al., 2006; Dimier et al., 2009). Finally, the values of the environmental parameters are chosen according to the conditions typical of the Strait of Sicily in the summer period. In particular, light intensity is estimated by using the remote sensing, while the other environmental parameters are fixed in agreement with experimental findings. The numerical values of the parameters are shown in Table 3.

We performed a preliminary analysis on the deterministic model, finding that the steady state is achieved at $t \approx 3 \times 10^{4} \mathrm{~h}$. Since the presence of noise sources does not cause significant changes in the time necessary to reach the stationary state, we solve the system (8)-(13) fixing as a maximum time $t_{\text {max }}=4 \times 10^{4} \mathrm{~h}$.

As initial condition we consider the abundances of Pelagophytes and Prochlorococcus concentrated in two layers close to the 
Table 3

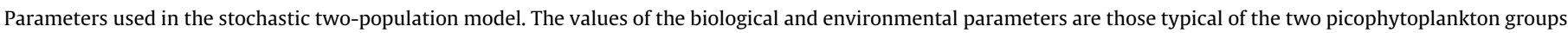
that coexist in the Strait of Sicily during the summer season.

\begin{tabular}{|c|c|c|c|}
\hline Symbol & Interpretation & Units & Value \\
\hline$a_{b g}$ & Background turbidity & $\mathrm{m}^{-1}$ & 0.045 \\
\hline$a_{1}$ & Absorption coefficient of picoeukaryotes & $\mathrm{m}^{2}$ cell $^{-1}$ & $3.3 \times 10^{-10}$ \\
\hline$a_{2}$ & Absorption coefficient of Prochlorococcus & $\mathrm{m}^{2}$ cell $^{-1}$ & $2.4 \times 10^{-15}$ \\
\hline$r_{1}$ & Maximum specific growth rate of picoeukaryotes & $\mathrm{h}^{-1}$ & 0.08 \\
\hline$r_{2}$ & Maximum specific growth rate of Prochlorococcus & $\mathrm{h}^{-1}$ & 0.07 \\
\hline$K_{I_{1}}$ & Half-saturation constant of light-limited growth of picoeukaryotes & $\mu \mathrm{mol}$ photons $\mathrm{m}^{-2} \mathrm{~s}^{-1}$ & 20 \\
\hline$K_{R_{1}}$ & Half-saturation constant of nutrient-limited growth of picoeukaryotes & mmol nutrient $\mathrm{m}^{-3}$ & 0.0425 \\
\hline$K_{I_{2}}$ & Half-saturation constant of light-limited growth of Prochlorococcus & $\mu \mathrm{mol}$ photons $\mathrm{m}^{-2} \mathrm{~s}^{-1}$ & 98 \\
\hline$K_{R_{2}}^{2}$ & Half-saturation constant of nutrient-limited growth of Prochlorococcus & mmol nutrient $\mathrm{m}^{-3}$ & 0.0150 \\
\hline$m_{1}$ & Specific loss rate of picoeukaryotes & $\mathrm{h}^{-1}$ & 0.01 \\
\hline$m_{2}$ & Specific loss rate of Prochlorococcus & $\mathrm{h}^{-1}$ & 0.01 \\
\hline $1 / Y_{1}$ & Nutrient content of picoeukaryotes & mmol nutrient cell ${ }^{-1}$ & $0.6 \times 10^{-9}$ \\
\hline $1 / Y_{2}$ & Nutrient content of Prochlorococcus & mmol nutrient cell ${ }^{-1}$ & $4 \times 10^{-15}$ \\
\hline$\epsilon_{1}$ & Nutrient recycling coefficient of picoeukaryotes & dimensionless & 0.5 \\
\hline$\epsilon_{2}$ & Nutrient recycling coefficient of Prochlorococcus & dimensionless & 0.5 \\
\hline$v_{1}$ & Sinking velocity of picoeukaryotes & $\mathrm{m} \mathrm{h}^{-1}$ & 0.0042 \\
\hline$v_{2}$ & Sinking velocity of Prochlorococcus & $\mathrm{m} \mathrm{h}^{-1}$ & 0.0042 \\
\hline$c_{1}$ & Chl-a cellular content of picoeukaryotes (as a function of depth) & fg chl-a cell ${ }^{-1}$ & $10.00-660.00$ \\
\hline$c_{2}$ & Dvchl-a cellular content of Prochlorococcus (as a function of depth) & fg Dvchl-a cell ${ }^{-1}$ & $0.25-2.20$ \\
\hline$D$ & Vertical turbulent diffusivity & $\mathrm{cm}^{2} \mathrm{~s}^{-1}$ & 3.0 \\
\hline$I_{\text {in }}$ & Incident light intensity & $\mu \mathrm{mol}$ photons $\mathrm{m}^{-2} \mathrm{~s}^{-1}$ & 1383.19 \\
\hline$R_{\text {in }}$ & Nutrient concentration at $z_{b}$ & mmol nutrient $\mathrm{m}^{-3}$ & 6.0 \\
\hline$z_{b}$ & Depth of the water column & $\mathrm{m}$ & 575 \\
\hline
\end{tabular}

deep chlorophyll maximum observed in the experimental data. Concerning the initial nutrient concentration, this is set at a constant value from the water surface up to the DCM, while increases linearly below the DCM up to the seabed (Denaro et al., 2013b,c).

To compare the theoretical distributions with the experimental profiles, the numerical cell concentrations of Pelagophytes and Prochlorococcus have to be converted into chl $a$ and Dvchl $a$ concentrations, respectively, using the two curves of mean vertical profile obtained by Brunet et al. (Brunet et al., 2006, 2007). We recall that the role of the conversion curves is very important in our analysis because these allow to compare the results of statistical tests obtained by using the one-population model, with those coming by the two-population model. Indeed, this quantitative comparison among the models has never carried out in previous works (Shigesada and Okubo, 1981; Klausmeier and Litchman, 2001; Huisman et al., 2002, 2006; Ryabov and Blausius, 2008; Ryabov et al., 2010; Ryabov and Blasius, 2011; Ryabov, 2012).

Moreover, we consider the total quantity of chl $a$ and Dvchl $a$ concentration due to other phytoplankton groups present along the water column (Denaro et al., 2013a,b). Therefore, we add the numerical concentrations with $\Delta b_{(D v) c h l a}$ and obtain the stationary distribution of total chlorophyll concentration in deterministic $\left(\sigma_{b_{1}}=\sigma_{b_{2}}=\sigma_{R}=0\right)$ and stochastic regime. Specifically, in our stochastic analysis we distinguished two different cases: (1) the environmental noise affects only the phosphorus concentration $\left(\sigma_{b_{1}}=\sigma_{b_{2}}=0\right.$ and $\left.\sigma_{R} \neq 0\right)$; (2) the effects of random fluctuations

Table 4

Case 1 . Results of $\chi^{2}$, reduced chi-square $\left(\tilde{\chi}^{2}\right)$, and Kolmogorov-Smirnov goodnessof-fit tests for sampling site $\left(35^{\circ} 18.17^{\prime} \mathrm{N}, 13^{\circ} 44.44^{\prime} \mathrm{E}\right)$ for different values of $\sigma_{R} . \mathrm{D}(\mathrm{K}-\mathrm{S})$ and $\mathrm{P}(\mathrm{K}-\mathrm{S})$ are the maximum difference between the cumulative distributions and the corresponding probability for the K-S test, respectively. The number of samples, used for the tests and distanced of $1 \mathrm{~m}$, is $n=200$ corresponding to consider from the surface the first $200 \mathrm{~m}$ of depth.

\begin{tabular}{lllll}
\hline$\sigma_{R}$ & $\chi^{2}$ & $\tilde{\chi}^{2}$ & $\mathrm{D}(\mathrm{K}-\mathrm{S})$ & $\mathrm{P}(\mathrm{K}-\mathrm{S})$ \\
\hline 0.0000 & 0.23 & 0.0012 & 0.0812 & 0.517 \\
0.0015 & 0.19 & 0.0009 & 0.0609 & 0.847 \\
0.0020 & 0.18 & 0.0009 & 0.0609 & 0.847 \\
0.0025 & 0.18 & 0.0009 & 0.0660 & 0.771 \\
0.0050 & 0.19 & 0.0010 & 0.0711 & 0.687 \\
0.0100 & 0.32 & 0.0016 & 0.1066 & 0.201 \\
\hline
\end{tabular}

are considered in the dynamics of Pelagophytes, Prochlorococcus and nutrient $\left(\sigma_{b_{1}} \neq 0, \sigma_{b_{2}} \neq 0\right.$ and $\left.\sigma_{R} \neq 0\right)$.

Case 1. The average theoretical distributions of the total chl a and Dvchl $a$ concentration are shown in Fig. 4. Here, one can see a decrease in the magnitude of the total chlorophyll a concentration. Moreover a deeper localization of the DCM, respect to the deterministic approach, is present also for low noise intensities ( $\sigma_{R}$ between 0.0015 and 0.0100 ).

The results of $\chi^{2}$ goodness-of-fit test and Kolmogorov-Smirnov (K-S) test are shown in Table 4. Performing the comparison with Table 2, the results of the statistical analysis show that the stochastic two-population model reproduces the experimental profile of total chl $a$ and Dvchl $a$ concentration better than the onepopulation model. In particular, the $\chi^{2}$ test exhibits the best value of reduced chi-square for two different noise intensities, i.e. $\sigma_{R}=0.0020$ and $\sigma_{R}=0.0025$. At the same time, analyzing the results of the K-S test, we get the best agreement between experimental and theoretical distributions for $\sigma_{R}=0.0015$ and $\sigma_{R}=0.0020$. Conversely, the results of the K-S test performed in the one-population analysis were obtained but are not shown here, since $P(K-S)=0$ for all values of the noise intensity considered. Moreover, the statistical results obtained in this section indicate that, for suitable values of the noise intensity, the stochastic twopopulation model reproduces the experimental data better than the deterministic one (see Table 4).

In Fig. 5 we show the behaviour of the depth, width, and magnitude of the DCM as a function of $\sigma_{R}$. The results indicate that the depth of the DCM slightly increases as a function of the noise intensity (see panel b), in agreement with the behaviour observed in the case of the one-population system. Moreover, we note a decrease of the total concentration of chl $a$ and Dvchl $a$ in the DCM of the site studied (see panel a), connected with an increase of the width of the DCM (see panel c). This is a behaviour already observed in the one-population system.

Finally, results here not reported show that the phytoplankton groups tends to disappear for $\sigma_{R}>0.01$. The present analysis confirms the result found in the one-population study: (i) the nutrient concentration plays a crucial role in the stability of the phytoplankton populations; (ii) the presence of noise sources directly acting on the phosphorus concentration could explain the disappearance of the picophytoplankton groups. 

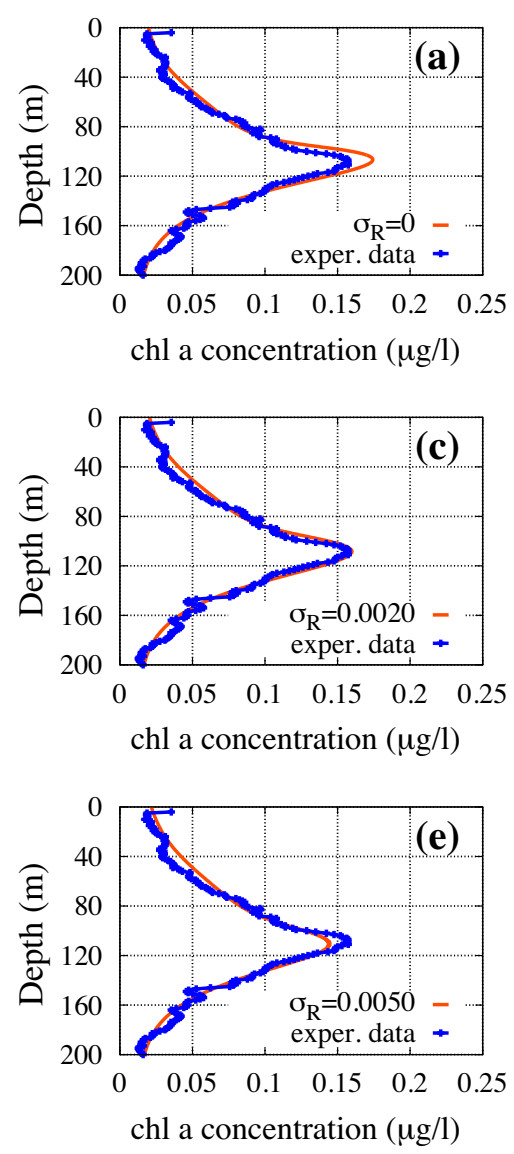
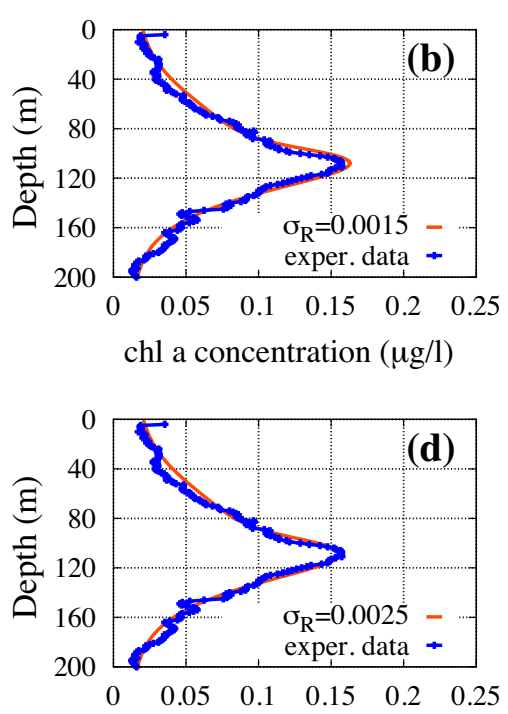

chl a concentration $(\mu \mathrm{g} / \mathrm{l})$

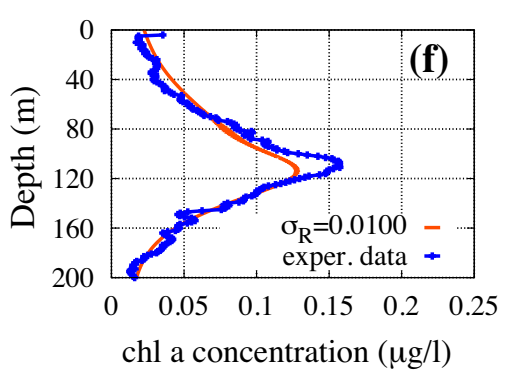

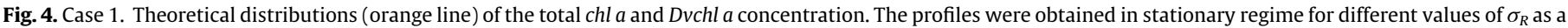

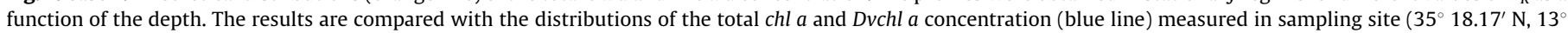

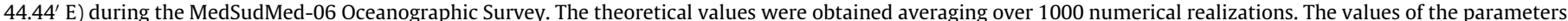

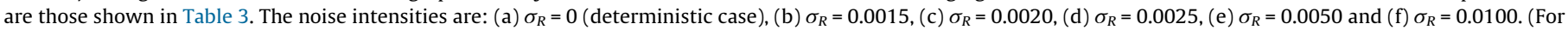
interpretation of the references to color in this figure legend, the reader is referred to the web version of this article.)
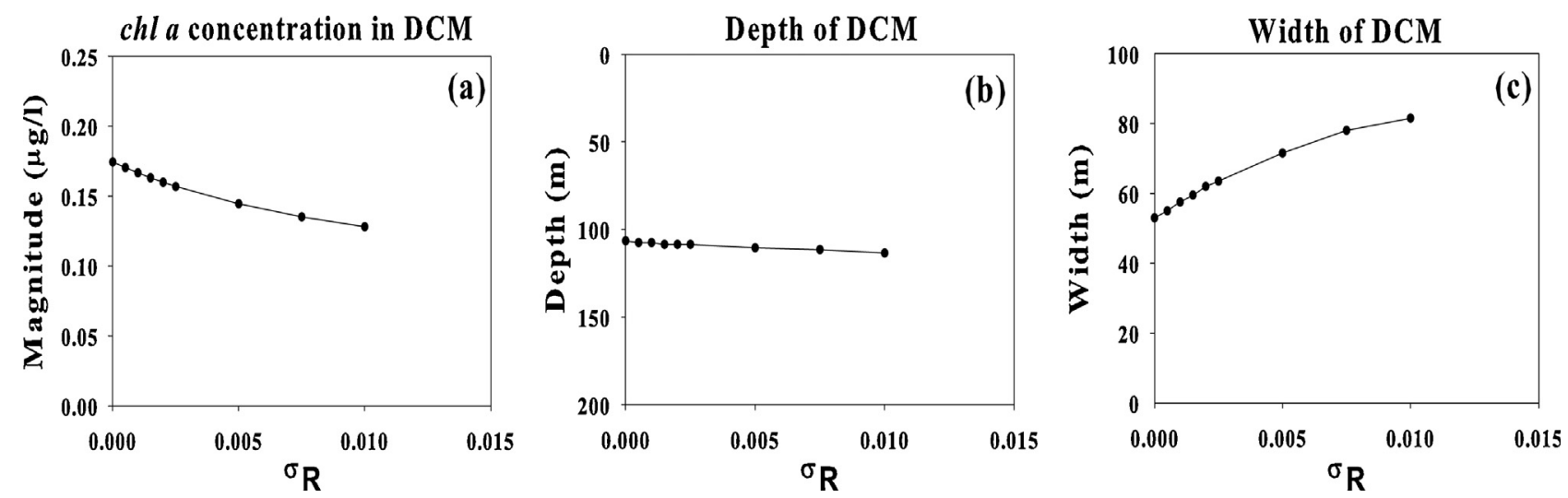

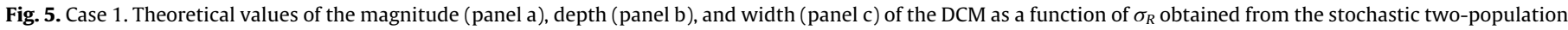
model for sampling site $\left(35^{\circ} 18.17^{\prime} \mathrm{N}, 13^{\circ} 44.44^{\prime} \mathrm{E}\right)$. The values shown have been calculated at the steady state.

Case 2. The theoretical profiles of the total concentration of chl a and Dvchl $a$ are shown in Fig. 6 together with experimental distributions. In this case, for suitable values of the noise intensity $\left(\sigma_{b_{1}}=0.15, \sigma_{b_{2}}=0.10\right.$ and $\left.\sigma_{R}=0.0020\right)$, the $\chi^{2}$ goodness-of-fit test assumes a value of the reduced chi-square $\left(\tilde{\chi}^{2}=0.0008\right)$ lower than those previously obtained from the stochastic two-population model with $\sigma_{b_{1}}=\sigma_{b_{2}}=0$ (see Table 4). Viceversa, the statistical parameters, $D(K-S)$ and $P(K-S)$, indicate a worse agreement between numerical results and experimental data respect to the stochastic dynamics with only one multiplicative noise source. Therefore, contrasting indications come from the $\chi^{2}$ and K-S tests on the role of the noise in the modelling of the real dynamics of the two phytoplankton groups. However, also in this case, the results of both tests indicate that, respect to the stochastic one-population model, the two-population model provides theoretical results in a better agreement with the experimental findings (Valenti et al., 2012; Denaro et al., 2013a).

In general, the results obtained from the stochastic twopopulation model indicate that the presence of a noise source, directly acting on the dynamics of the nutrient concentration due 


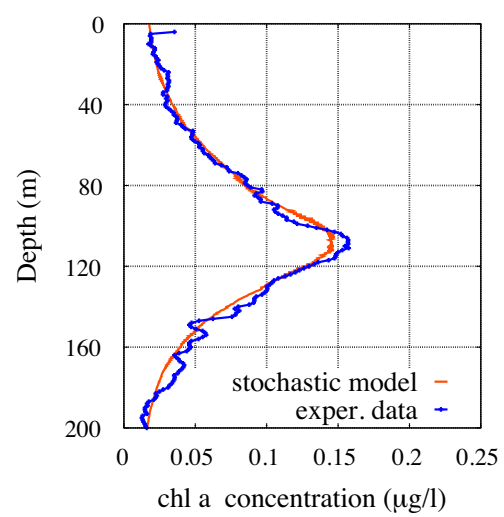

Fig. 6. Case 2. Theoretical distributions (orange line) of the total chl $a$ and Dvchl $a$ concentration. The profiles were obtained in stationary regime for a given set of noise intensities as a function of the depth, and are compared with the corresponding experimental distributions (blue line) in sampling site $\left(35^{\circ}\right.$ $18.17^{\prime} \mathrm{N}, 13^{\circ} 44.44^{\prime} \mathrm{E}$ ) during the MedSudMed-06 Oceanographic Survey. The theoretical values were obtained averaging over 1000 numerical realizations. The values of the parameters are those shown in Table 3. The noise intensities are: $\sigma_{b_{1}}=0.15, \sigma_{b_{2}}=0.10$ and $\sigma_{R}=0.0020$. (For interpretation of the references to color in this figure legend, the reader is referred to the web version of this article.)

to the random changes in physical variables, such as temperature and velocities field, contributes to a more precise description of the spatio-temporal behaviour of the total chl $a$ and Dvchl $a$ concentration in the marine site analyzed. Moreover, the presence of several multiplicative noise sources, which act on the dynamics of phytoplankton populations and nutrient, can allow to further improve the agreement between theoretical results and experimental findings.

On the basis of the numerical results obtained by one- and twopopulation model, we can conclude that the theoretical analysis should be based on a stochastic approach which takes into account the real environmental conditions. This could be the beginning of a new "idea" of modelling for the spatio-temporal distributions of phytoplankton biomass: a class of models able to reproduce the real dynamics as observed in experimental measurements and eventually capable of predicting future changes, produced by global warming, in phytoplankton distributions (Grenfell et al., 1998; Zimmer, 1999; Bjornstad and Grenfell, 2001).

\section{Five-population model}

In this section, we introduce a stochastic reaction-diffusiontaxis model to simulate the spatio-temporal behaviour of five picophytoplankton groups in the Tyrrhenian Sea, during four different periods of the year. In particular, on the basis of the field observations, here we also consider the dynamics of two further picophytoplankton populations, i.e Synechococcus and Haptophytes, which give a significative contribution to the total chl a concentration during autumn and winter seasons, when the presence of an upper mixed layer causes the upwelling of nutrients from the deeper layers (Patti et al., 2010; Basilone et al., 2013; Bonanno et al., 2014; Rinaldi et al., 2014; Valenti et al., 2015). Moreover, the use of the conversion curves allows to identify the contribution of each ecotype of Prochlorococcus on the total chl a concentration. In fact, several authors believe that the Prochlorococcus HL dominates the intermediate layers of the Tyrrhenian Sea giving a chlorophyll contribution much higher respect to the Prochlorococcus LL, mainly localized in deeper layers (Garczarek et al., 2007; Mella-Flores et al., 2011). Therefore, the analysis is performed on phytoplankton populations belonging to two different domains, i.e. picoeukarytotes and picoprokaryotes, which account about for $80 \%$ of the total chlorophyll $a$ on average in the
Mediterranean Sea. Specifically, the picoprokaryotes domain is composed by Synechococcus and Prochlorococcus (HL-ecotype and LL-ecotype), while picoeukaryotes domain is mainly represented by Haptophytes and Pelagophytes (Garczarek et al., 2007; Mella-Flores et al., 2011; La Ferla et al., 2012).

According to the procedure followed in the previous sections, we reproduce the vertical profiles of $\mathrm{chl}$ a concentration collected in sampling site $\left(39^{\circ} 30.00^{\prime} \mathrm{N}, 13^{\circ} 30.00^{\prime} \mathrm{E}\right)$ located in the Tyrrhenian Sea, inside the Modified Atlantic Water (MAW), that is the upper layer of the water column of the Mediterranean Sea (from the surface down to $200 \mathrm{~m}$ ). This layer corresponds to the euphotic zone of the water column, where the growth of phytoplankton is allowed.

In this study we introduce three novelties respect to the analysis carried out in the previous cases (one- and two-population models): (i) the coexistence of five picophytoplankton populations in heterogenous habitat; (ii) the effects of the seasonal changes of physical variables on the population dynamics; (iii) the active movement of the phytoplankton populations considered by using a taxis term.

The competition of the five phytoplankton populations for the two limiting factors, i.e. light intensity and nutrient concentration, in heterogenous environment is the first novelty introduced in this study. During the last years, several authors have debated about competition models in which the coexistence at equilibrium among several planktonic groups is associated with only few resources potentially limiting. This issue has been faced for the first time by Huisman and Weissing (1999), who proposed an explanation for biodiversity based on the features of the competition dynamics itself. In particular, they explained why in real ecosystems several plankton populations coexist, in spite of the "paradox of the plankton", which predicts that the number of species cannot exceeds the number of limiting resources in a constant and homogenous environment (Huisman and Weissing, 1999). Specifically, the authors show that the competition process among three or more species, for three limiting resources, causes oscillating (or chaotic) trajectories for the dynamics of all phytoplankton groups involved. This behaviour is explained by the non-equilibrium conditions, which allow the coexistence of several planktonic groups, also when their number is larger than that of the limiting resources (Huisman and Weissing, 1999; Huisman et al., 2002). Anyway, this fascinating theory can not be applied to real marine ecosystems, because the field observations show that both the spatial heterogeneity along the water column and the temporal variability of the physical quantities are always guaranteed during the whole year, reducing the size of the parameter region for which oscillating and chaotic regimes can occur. Indeed, in the Tyrrhenian Sea, the experimental data indicate the presence of an upper mixed layer, where the vertical turbulent diffusivity and light intensity assume values greater than those of deeper layers, determining heterogeneous conditions for the phytoplankton habitat. Moreover, the physical variables are subject to seasonal changes due to fluctuating weather conditions. Under these two conditions, i.e. spatial heterogeneity and temporal variability, the values of the biological and environmental parameters, estimated on the basis of experimental findings, are such as to avoid oscillating trajectories in the phytoplankton dynamics and keep the system far from the chaos (Ryabov and Blausius, 2008; Ryabov et al., 2010).

The second novelty introduced for the first time in the fivepopulation model is that of considering the effects of the seasonal changes of physical variables on the population dynamics. In particular, the real conditions of the marine ecosystem are reproduced by considering the water column stratification. More specifically, the influence of the upper mixed layer on the population dynamics has been analyzed by replacing the vertical 
turbulent diffusivity with a generalized Fermi function, varying with the depth and time. Moreover, we also take into account the effect of the periodical variations of incident light intensity on the phytoplankton dynamics by using the daily average values estimated for all days of the year.

The third novelty, presented in this study in accordance with Klausmeier and Litchman (2001), allows to consider the active movement of the picophytoplankton populations, which depends on the growing conditions along the water column (Klausmeier and Litchman, 2001). Specifically, in the differential equation of the phytoplankton dynamics, the advection term is replaced by a taxis term, where the swimming velocity of each population changes direction according to the sign of gradient of its net growth rate.

Finally, as in the two previous models, we consider a term of multiplicative Gaussian noise in the differential equation of nutrient dynamics.

\subsection{The stochastic five-population model}

Using a stochastic reaction-diffusion-taxis model, we reproduce the dynamics of the cell concentrations of the five populations considered, i.e. Synechococcus, Haptophytes, Prochlorococcus HL, Pelagophytes and Prochlorococcus LL, indicated by $b_{1}(z, t), b_{2}(z, t), b_{3}(z, t), b_{4}(z, t)$ and $b_{5}(z, t)$, respectively. Moreover, the vertical distributions of the nutrient concentration $R(z, t)$ and light intensity $I(z, t)$ are obtained.

We recall that the spatio-temporal behaviour of the picophytoplankton groups depends on three processes: growth, loss, and movement. According to previous works (Klausmeier and Litchman, 2001; Denaro et al., 2013a,b; Valenti et al., 2015), in our model the first two factors are described by using the net per capita growth rate (Klausmeier and Litchman, 2001; Valenti et al., 2015), defined as

$G_{i}(z, t)=\min \left(f_{R_{i}}(R(z, t)), f_{I_{i}}(I(z, t))\right)-m_{i}$.

Here, $f_{I_{i}}(I)$ and $f_{R_{i}}(R)$ are given by the Michaelis-Menten formulas (see Section 3 ), while $m_{i}$ is the specific loss rate of the $i$-th picophytoplankton group.

Conversely, the differential equations for the picophytoplankton dynamics are modified, respect to one- and two-population studies, in order to consider both the passive movement, due to the turbulence (Ryabov et al., 2010), and the active movement of each group (Klausmeier and Litchman, 2001).

The passive movement of all phytoplankton groups is modeled by the vertical turbulent diffusivity, $D(z, t)$, which changes as a function of the time, assuming uniformly larger values $D_{U}(t)$ in the upper mixed layer (Denman and Gargett, 1983; Oakey and Elliott, 1982; Massel, 1999) and uniformly smaller values $D_{D}(t)$ in the deeper layers (Peters et al., 1988; Ryabov et al., 2010; Denaro et al., 2013b,c; Valenti et al., 2015). The gradual transition from the upper mixed layer to deeper layers is described in terms of the following generalized Fermi function (Ryabov et al., 2010; Valenti et al., 2015)

$D(z, t)=D_{D}(t)+\frac{D_{U}(t)-D_{D}(t)}{1+\exp ^{\left(z-Z_{U}(t)\right) / w}}$,

where $Z_{U}(t)$ is the thickness of the upper mixed layer varying with the time, and the parameter $w$ is the width of the transient layer.

The active movement of the single microorganisms is modeled by a taxis term, where the swimming velocity $v_{i}$ of each population is a function of the gradient of the net growth rate $\left(\partial G_{i}(z, t) / \partial z\right)$ (Klausmeier and Litchman, 2001). Specifically, we use a step function (Klausmeier and Litchman, 2001; Valenti et al., 2015), defined as $v_{i}=+v_{i}^{s}$ if $\partial G_{i}(z, t) / \partial z>0, v_{i}=-v_{i}^{s}$ if $\partial G_{i}(z, t) / \partial z<0$, and $v_{i}=0$ if $\partial G_{i}(z, t) / \partial z=0$, where $v_{i}^{s}$ is a constant parameter, whose value (positive) is estimated for each population by using the same criteria adopted by Raven (1998).

Moreover, we consider the effects of the random fluctuations of environmental variables, by inserting in the differential equation for the phosphorus dynamics a term of spatially uncorrelated noise with the same statistical properties defined in Subsection 3.1. Finally, the light intensity $I(z, t)$ is assumed to decrease exponentially according to the Lambert-Beer's law (Hickman et al., 2010; Shigesada and Okubo, 1981; Kirk, 1994; Valenti et al., 2015), which is a function varying with the depth $z$ and the chlorophyll concentration $\operatorname{chla}_{i}(z, t)$ due to the presence of each picophytoplankton group (Valenti et al., 2015). The stochastic fivepopulation $(i=1, \ldots, 5)$ model is defined by the following equations:

$$
\begin{aligned}
\frac{\partial b_{i}(z, t)}{\partial t}= & b_{i} G_{i}(z, t)+\frac{\partial}{\partial z}\left[D(z, t) \frac{\partial b_{i}(z, t)}{\partial z}\right] \\
& -v_{i}\left(\frac{\partial G_{i}(z, t)}{\partial z}\right) \frac{\partial b_{i}(z, t)}{\partial z}
\end{aligned}
$$

$$
\begin{aligned}
\frac{\partial R(z, t)}{\partial t} & =-\sum \frac{b_{i}(z, t)}{Y_{i}} \cdot \min \left(f_{I_{i}}(I), f_{R_{i}}(R)\right)+\frac{\partial}{\partial z}\left[D(z, t) \frac{\partial R(z, t)}{\partial z}\right] \\
& +\sum \varepsilon_{i} m_{i} \frac{b_{i}(z, t)}{Y_{i}}+R \xi_{R}(z, t)
\end{aligned}
$$

$I(z, t)=I_{\text {in }}(t) \exp \left\{-\int_{0}^{z}\left[\sum a_{i} \cdot \operatorname{chla}_{i}(Z, t)+a_{b g}\right] d Z\right\}$,

where $\varepsilon_{i}, m_{i}$, and $1 / Y_{i}$ are nutrient recycling coefficient, specific loss rate, and nutrient content of the ith picophytoplankton group, respectively; $a_{i}$ are the chl $a$-normalized average absorption coefficients of the $i$ th picophytoplankton group, and $a_{b g}$ is the background turbidity; $I_{i n}(t)$ is the incident light intensity at the water surface, varying with the time due to daily changes.

The boundary conditions for cell concentration of the $i$-th picophytoplankton group are

$\left.\left[D(z, t) \frac{\partial b_{i}}{\partial z}-v_{i} b_{i}\right]\right|_{z=0}=\left.\left[D(z, t) \frac{\partial b_{i}}{\partial z}-v_{i} b_{i}\right]\right|_{z=z_{b}}=0$

where $z_{b}$ is the depth of MAW. Moreover, the boundary conditions for nutrient are described, in accordance with the stochastic twopopulation model, by the following equations

$\left.\frac{\partial R}{\partial z}\right|_{z=0}=0, \quad R\left(z_{b}\right)=R_{\text {in }}$.

Eqs. (16)-(20) describe mathematically the stochastic reactiondiffusion-taxis model used to reproduce the spatio-temporal dynamics of the five picophytoplankton populations studied in this work.

\subsection{Results of the stochastic five-population model}

In this subsection, the theoretical distributions of cell concentration for the five picophytoplankton groups are obtained by integrating the differential equations and averaging over 1000 realizations. In this case, we use a numerical method based on an explicit finite difference scheme with centered-in-space differencing for the diffusion term and upwind differencing for the taxis term. Moreover, the increment of the spatial variable and the time step are fixed at $0.5 \mathrm{~m}$ and $0.05 \mathrm{~h}$, respectively, in order to obtain the stability conditions for both differencing terms (Roache, 1976, 
Table 5

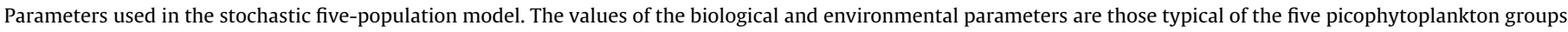
that coexist in the Tyrrhenian Sea during the whole year.

\begin{tabular}{|c|c|c|c|}
\hline Symbol & Interpretation & Units & Value \\
\hline$a_{b g}$ & Background turbidity & $\mathrm{m}^{-1}$ & 0.060 \\
\hline$a_{1}$ & Average absorption coefficient of Synechococcus & $\mathrm{m}^{2} \mathrm{mg} \mathrm{chl- \textrm {a } ^ { - 1 }}$ & 0.025 \\
\hline$a_{2}=a_{4}$ & Average absorption coefficient of picoeukaryotes & $\mathrm{m}^{2} \mathrm{mg}$ chl-a ${ }^{-1}$ & 0.012 \\
\hline$a_{3}$ & Average absorption coefficient of Prochlorococcus HL & $\mathrm{m}^{2} \mathrm{mg}$ chl-a ${ }^{-1}$ & 0.016 \\
\hline$a_{5}$ & Average absorption coefficient of Prochlorococcus LL & $\mathrm{m}^{2} \mathrm{mg}$ chl-a ${ }^{-1}$ & 0.027 \\
\hline$a_{6}$ & Average absorption coefficient of phytoplankton $>3 \mu \mathrm{m}$ & $\mathrm{m}^{2} \mathrm{mg}$ chl-a ${ }^{-1}$ & 0.020 \\
\hline$r_{1}$ & Maximum specific growth rate of Synechococcus & $\mathrm{h}^{-1}$ & 0.058 \\
\hline$r_{2}$ & Maximum specific growth rate of Haptophytes & $\mathrm{h}^{-1}$ & 0.079 \\
\hline$r_{3}$ & Maximum specific growth rate of Prochlorococcus HL & $\mathrm{h}^{-1}$ & 0.088 \\
\hline$r_{4}$ & Maximum specific growth rate of Pelagophytes & $\mathrm{h}^{-1}$ & 0.096 \\
\hline$r_{5}$ & Maximum specific growth rate of Prochlorococcus LL & $\mathrm{h}^{-1}$ & 0.031 \\
\hline$K_{I_{1}}$ & Half-saturation constant of light-limited growth of Synechococcus & $\mu \mathrm{mol}$ photons $\mathrm{m}^{-2} \mathrm{~s}^{-1}$ & 70.00 \\
\hline$K_{I_{2}}$ & Half-saturation constant of light-limited growth of Haptophytes & $\mu \mathrm{mol}$ photons $\mathrm{m}^{-2} \mathrm{~s}^{-1}$ & 90.00 \\
\hline$K_{I_{3}}$ & Half-saturation constant of light-limited growth of Prochlorococcus HL & $\mu \mathrm{mol}$ photons $\mathrm{m}^{-2} \mathrm{~s}^{-1}$ & 40.00 \\
\hline$K_{I_{4}}$ & Half-saturation constant of light-limited growth of Pelagophytes & $\mu \mathrm{mol}$ photons $\mathrm{m}^{-2} \mathrm{~s}^{-1}$ & 35.00 \\
\hline$K_{I_{5}}$ & Half-saturation constant of light-limited growth of Prochlorococcus LL & $\mu \mathrm{mol}$ photons $\mathrm{m}^{-2} \mathrm{~s}^{-1}$ & 6.00 \\
\hline$K_{R_{1}}$ & Half-saturation constant of nutrient-limited growth of Synechococcus & mmol phosphorus $\mathrm{m}^{-3}$ & 0.00001 \\
\hline$K_{R_{2}}$ & Half-saturation constant of nutrient-limited growth of Haptophytes & mmol phosphorus $\mathrm{m}^{-3}$ & 0.00004 \\
\hline$K_{R_{3}}=K_{R_{5}}$ & Half-saturation constant of nutrient-limited growth of Prochlorococcus HL & mmol phosphorus $\mathrm{m}^{-3}$ & 0.00200 \\
\hline$K_{R_{4}}$ & Half-saturation constant of nutrient-limited growth of Pelagophytes & mmol phosphorus $\mathrm{m}^{-3}$ & 0.01190 \\
\hline$m_{1}$ & Specific loss rate of Synechococcus & $\mathrm{h}^{-1}$ & 0.014 \\
\hline$m_{2}=m_{4}$ & Specific loss rate of picoeukaryotes & $\mathrm{h}^{-1}$ & 0.010 \\
\hline$m_{3}=m_{5}$ & Specific loss rate of Prochlorococcus & $\mathrm{h}^{-1}$ & 0.011 \\
\hline $1 / Y_{1}$ & Nutrient content of Synechococcus & mmol phosphorus cell ${ }^{-1}$ & $2.86 \times 10^{-14}$ \\
\hline $1 / Y_{2}=1 / Y_{4}$ & Nutrient content of picoeukaryotes & mmol phosphorus cell ${ }^{-1}$ & $2.00 \times 10^{-12}$ \\
\hline $1 / Y_{3}=1 / Y_{5}$ & Nutrient content of Prochlorococcus & mmol phosphorus cell ${ }^{-1}$ & $1.33 \times 10^{-13}$ \\
\hline$\varepsilon_{1}$ & Nutrient recycling coefficient of Synechococcus & dimensionless & 0.51 \\
\hline$\varepsilon_{2}=\varepsilon_{4}$ & Nutrient recycling coefficient of picoeukaryotes & dimensionless & 0.52 \\
\hline$\varepsilon_{3}=\varepsilon_{5}$ & Nutrient recycling coefficient of Prochlorococcus & dimensionless & 0.52 \\
\hline$v_{1}^{s}$ & Magnitude of swimming velocity of Synechococcus & $\mathrm{m} \mathrm{h}^{-1}$ & 0.000088 \\
\hline$v_{2}^{s}=v_{4}^{s}$ & Magnitude of swimming velocity of picoeukaryotes & $\mathrm{m} \mathrm{h}^{-1}$ & 0.000098 \\
\hline$v_{3}^{s}=v_{5}^{s}$ & Magnitude of swimming velocity of Prochlorococcus & $\mathrm{m} \mathrm{h}^{-1}$ & 0.000039 \\
\hline$c_{1}$ & Chl-a cellular content of Synechococcus & fg chl-a cell ${ }^{-1}$ & 2.00 \\
\hline$c_{2}=c_{4}$ & Chl-a cellular content of picoeukaryotes (as a function of depth) & fg chl-a cell ${ }^{-1}$ & $10.00-660.00$ \\
\hline$c_{3}=c_{5}$ & Dvchl-a cellular content of Prochlorococcus (as a function of depth) & fg Dvchl-a cell ${ }^{-1}$ & $0.25-2.20$ \\
\hline$D_{U}$ & Vertical turbulent diffusivity in UML (as a function of time) & $\mathrm{cm}^{2} \mathrm{~s}^{-1}$ & $4.75-28.84$ \\
\hline$D_{D}$ & Vertical turbulent diffusivity below the thermocline (as a function of time) & $\mathrm{cm}^{2} \mathrm{~s}^{-1}$ & $1.25-5.75$ \\
\hline$I_{\text {in }}$ & Incident light intensity (as a function of time) & $\mu \mathrm{mol}$ photons $\mathrm{m}^{-2} \mathrm{~s}^{-1}$ & $314.36-1638.72$ \\
\hline$R_{\text {in }}$ & Nutrient concentration at $z_{b}$ & mmol phosphorus $\mathrm{m}^{-3}$ & 0.204 \\
\hline$z_{b}$ & Depth of the MAW & $\mathrm{m}$ & 200 \\
\hline
\end{tabular}

1998; Tveito and Winther, 1998; Veldman, 2001; Hundsdorfer and Verwer, 2003; Thi et al., 2005).

In order to reproduce the vertical profiles of chl a concentration collected in the sampling site during the four different oceanographic surveys, we fixed the biological and environmental parameters as reported in Table 5 .

The biological parameters of the five populations investigated have been set according to the experimental results obtained by other authors (Raven et al., 2005; Raven, 1998; Dimier et al., 2009; Veldhuis et al., 2005; Thingstad and Sakshaugh, 1990; Quevedo and Anadón, 2001; Moore et al., 1995, 1995; Bertilsson et al., 2003; Timmermans et al., 2005; Morel, 1997; Brunet et al., 2006, 2007, 2003; Hickman et al., 2010; Rippka et al., 2000). Specifically, the values of these parameters are chosen in order to guarantee the coexistence of all picophytoplankton groups (Huisman et al., 2006; Ryabov et al., 2010; Ryabov and Blasius, 2011; Denaro et al., 2013b,c) along the water column, during the whole year.

On the other side, the values of the environmental parameters have been estimated on the basis of experimental data collected in the sampling site of Tyrrhenian Sea during the period investigated (from 24 November 2006 to 9 June 2007). In particular, the vertical turbulent diffusivity in the deep layers $D_{D}(t)$ changes as a function of the time (Peters et al., 1988), taking on values typical of weakly mixed waters $\left(D_{D}(t) \leq 6.0 \mathrm{~cm}^{2} \mathrm{~s}^{-1}\right.$, in all seasons). Moreover, in accordance with the methods used by other authors (Denman and Gargett, 1983; Oakey and Elliott, 1982; Nishimura and Nakamura, 1987; Nakamura and Hayakawa, 1991; Massel, 1999; Justić et al.,
2002), the vertical turbulent diffusivity $D_{U}(t)$ and thickness $Z_{U}(t)$ of the UML are calculated by using the experimental profiles of temperature and density, collected in the same site during the different oceanographic surveys.

Finally, the daily average light intensities at the water surface, $I_{i n}(t)$, are estimated by using the remote sensing, while the average value of phosphorus concentration at the bottom of the MAW $\left(R_{i n}=0.204 \mathrm{mmol} \mathrm{m}^{-3}\right)$ is fixed in agreement with experimental data.

In this study, the preliminary analysis performed on the stochastic model showed that the stationary regime is reached at $t \approx 9 \times 10^{4} \mathrm{~h}$. Therefore, in order to obtain steady seasonally driven oscillations of picophytoplankton abundances and phosphorus concentration for the whole period investigated, we integrate the system (16)-(20) by fixing as a maximum time $t_{\max }=10^{5} \mathrm{~h}$.

As initial conditions, we assume for each picophytoplankton group a low cell concentration uniformly distributed along the water column in accordance with other authors (Ryabov et al., 2010), while the phosphorus concentration is set equal to zero from the water surface to the thermocline, with a linear increase below this point up to the end of MAW (Valenti et al., 2015).

According to previous studies, to compare the theoretical results with the experimental findings, the numerical cell concentrations of the five populations are converted into chl $a$ and Dvchl a concentrations, setting the cellular content of Synechococcus equal to $2 \mathrm{fg}$ chl $a$ cell $^{-1}$ (Morel, 1997), and using the curves of mean vertical profile for the other groups (Brunet 

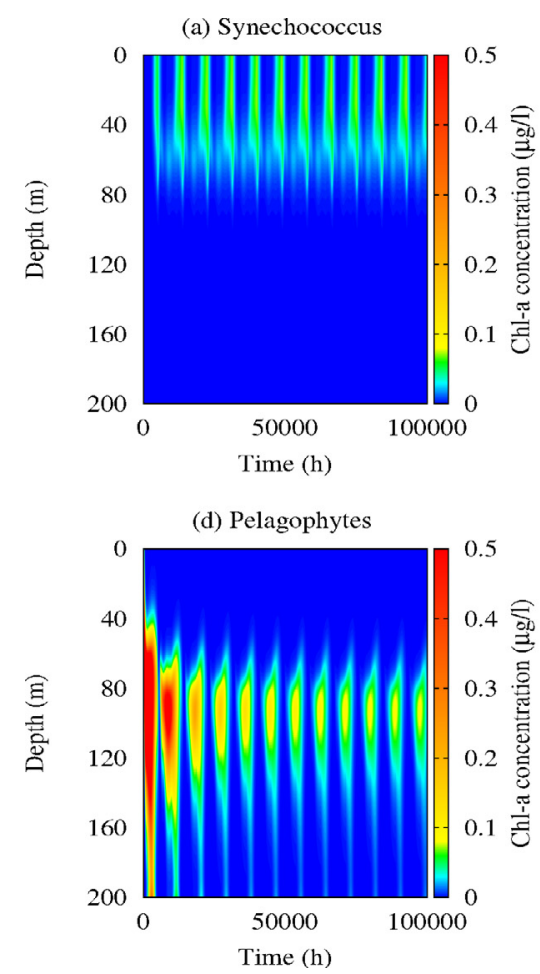

(b) Haptophytes

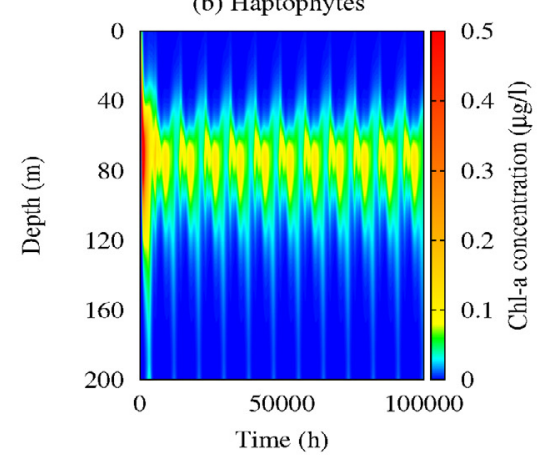

(e) Prochlorococcus LL

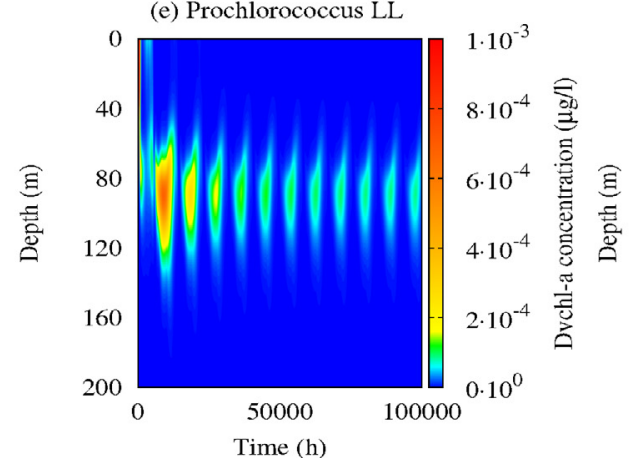

(c) Prochlorococcus HL

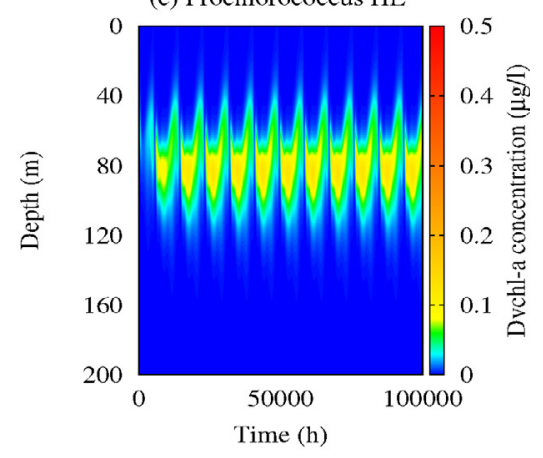

(f) Total chlorophyll-a

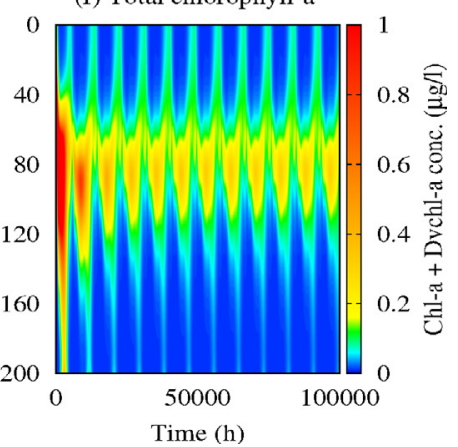

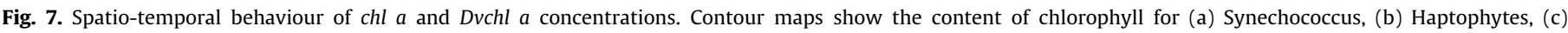

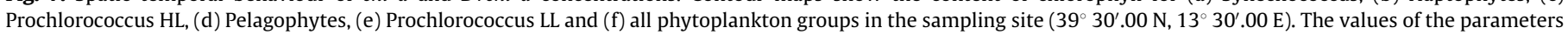
used in the model are those shown in Table 5. The noise intensity is $\sigma_{R}=0.0005$.

et al., 2006, 2007). In particular, it is worth stressing the key role assumed in this study by the conversion rate of Synechococcus, which allows to better reproduce the vertical profiles of chlorophyll concentration in the upper mixed layer during autumn and winter seasons, when the Synechococcus abundance reaches the maximum value. This represents a further novelty, introduced in the five-population model, useful to analyze the spatio-temporal behaviour of Synechococcus but never used by other authors.

Moreover, we recall that the fraction of nano- and microphytoplankton ( $>3 \mu \mathrm{m}$ ) is uniformly distributed in the MAW, and accounts about for $20 \%$ of the total quantity of chl $a$ and Dvchl a. Therefore, this quantity, $\Delta b_{(D v) \text { chla, }}$ which represents the contribution to the total chl a due to the groups with larger size, is estimated by using the experimental data. Finally, we add the numerical concentrations with $\Delta b_{(D v) c h l a}$, and obtain the spatiotemporal behaviour of the total chl $a$ and Dvchl $a$ concentration for different values of noise intensity.

In Fig. 7 we show the numerical results of the $(D v)$ chl a concentrations of the five picophytoplankton groups and the total chl $a$ and Dvchl $a$ concentration, obtained for a fixed noise intensity $\left(\sigma_{R}=0.0005\right)$. Here, we observe the presence of the chlorophyll peak for Haptophytes, Prochlorococcus HL and Pelagophytes in intermediate layers of the MAW, in correspondence of the experimental DCM, during the whole year. Moreover, the chlorophyll peak for Synechococcus is always observed close to the surface water in correspondence of the upper mixed layer, while that for Prochlorococcus LL is localized in deeper layers, where the chlorophyll concentration assumes very low values during the whole year, in accordance with experimental data collected in Tyrrhenian Sea and analyzed in previous works (Garczarek et al., 2007; Mella-Flores et al., 2011). Therefore, the analysis performed by the five-population model indicates that the Prochlorococcus HL-ecotype prevails on the LL-ecotype in the Tyrrhenian Sea.
In general, the theoretical results show that both the depth and magnitude of the chlorophyll peak, associated with each phytoplankton population, are in a good qualitative agreement with the experimental findings (results here not reported) obtained by the HPLC analysis of the bottle samples collected during the oceanographic surveys. Moreover, the qualitative comparison between numerical results and experimental data indicates that the five-population model reproduces correctly the spatiotemporal behaviour of each phytoplankton population during the whole period investigated. In conclusion, these findings prove the goodness of our analysis, carried out on the basis of experimental data, differently from previous works by other authors, in which no comparison with field observations were performed.

In Fig. 8 we compare the experimental profiles of chlorophyll a concentration with the corresponding theoretical distributions, extracted from the contour maps obtained for different noise intensities.

Here, we observe a good agreement between experimental data (blue line) and numerical results (orange line) in four different periods (seasons) of the year, when environmental random fluctuations are included, through a term of multiplicative noise, in the equation for the nutrient dynamics. Moreover, the results of the goodness-of-fit test $\chi^{2}$, for all sampling periods investigated, are shown in Table 6.

Here, one can see that the best value of reduced chi-square is obtained for a different value of the noise intensity, depending on the season considered. In particular, the best result of the reduced chi-square is obtained in late fall $\left(\tilde{\chi}^{2}=0.00589\right)$ for $\sigma_{R}=0.0010$, in winter $\left(\tilde{\chi}^{2}=0.00136\right)$ for $\sigma_{R}=0.0005$, in early spring $\left(\tilde{\chi}^{2}=0.00669\right)$ for $\sigma_{R}=0.0035$, and in late spring $\left(\tilde{\chi}^{2}=0.00669\right)$ for $\sigma_{R}=0$ (deterministic case). These results indicate that, in accordance with previous studies (Valenti et al., 2012; Denaro et al., 2013a,b,c), the stochastic five-population model represents 


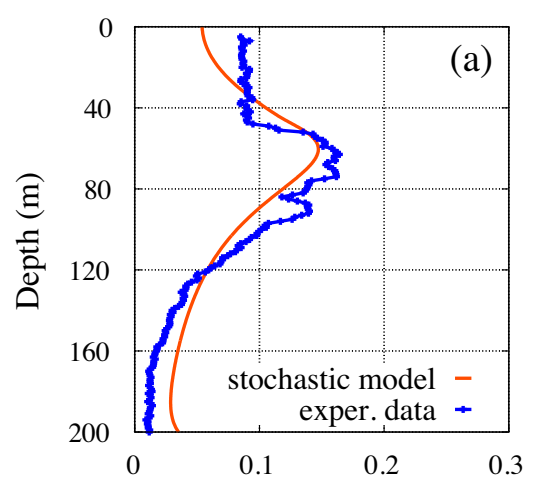

chl a concentration $(\mu \mathrm{g} / \mathrm{l})$

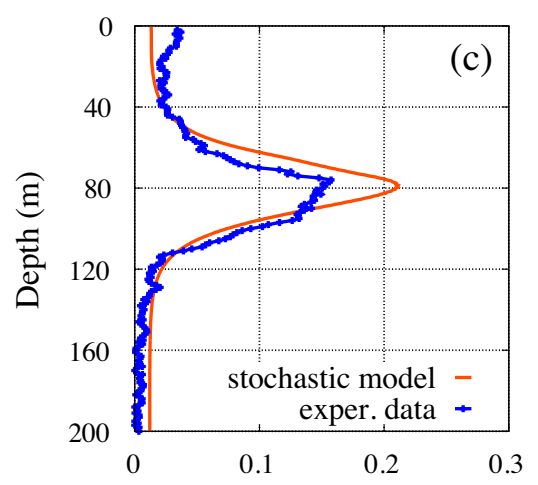

chl a concentration $(\mu \mathrm{g} / \mathrm{l})$

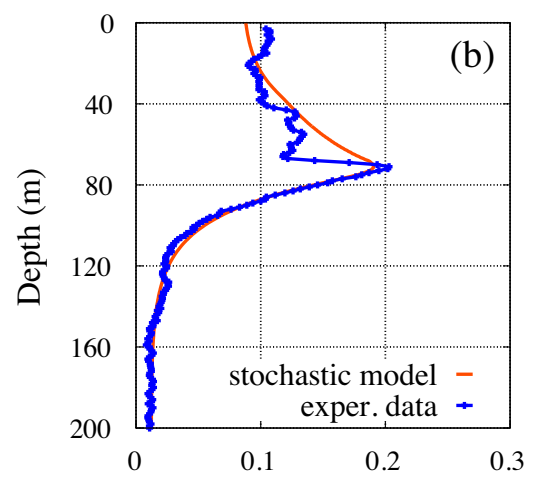

chl a concentration $(\mu \mathrm{g} / \mathrm{l})$

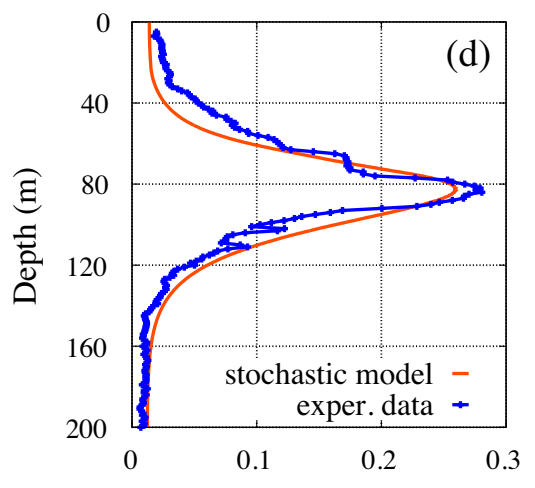

chl a concentration $(\mu \mathrm{g} / \mathrm{l})$

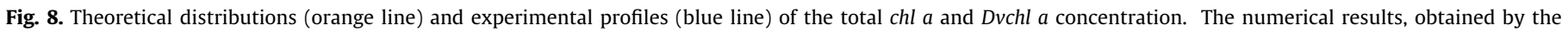

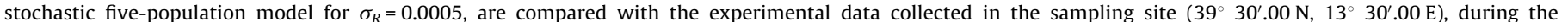

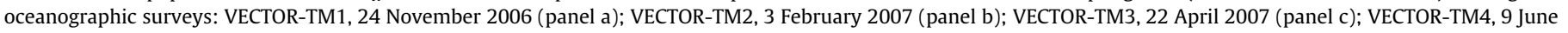
2007 (panel d). (For interpretation of the references to color in this figure legend, the reader is referred to the web version of this article.)

Table 6

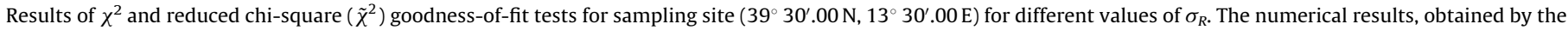

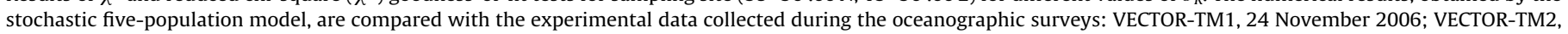

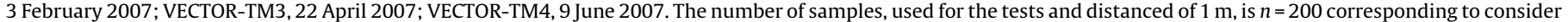
from the surface the first $200 \mathrm{~m}$ of depth.

\begin{tabular}{|c|c|c|c|c|c|c|c|c|}
\hline \multirow[t]{2}{*}{$\sigma_{R}$} & \multicolumn{2}{|c|}{24 November 2006} & \multicolumn{2}{|c|}{3 February 2007} & \multicolumn{2}{|c|}{22 April 2007} & \multicolumn{2}{|c|}{9 June 2007} \\
\hline & $\chi^{2}$ & $\tilde{\chi}^{2}$ & $\chi^{2}$ & $\tilde{\chi}^{2}$ & $\chi^{2}$ & $\tilde{\chi}^{2}$ & $\chi^{2}$ & $\tilde{\chi}^{2}$ \\
\hline 0.0000 & 1.167 & 0.00595 & 0.282 & 0.00144 & 1.323 & 0.00675 & 1.312 & 0.00669 \\
\hline 0.0005 & 1.154 & 0.00589 & 0.267 & 0.00136 & 1.316 & 0.00671 & 1.342 & 0.00685 \\
\hline 0.0010 & 1.154 & 0.00589 & 0.268 & 0.00137 & 1.314 & 0.00671 & 1.365 & 0.00697 \\
\hline 0.0025 & 1.154 & 0.00589 & 0.272 & 0.00139 & 1.312 & 0.00669 & 1.411 & 0.00720 \\
\hline 0.0035 & 1.154 & 0.00589 & 0.274 & 0.00140 & 1.312 & 0.00669 & 1.425 & 0.00727 \\
\hline
\end{tabular}

an improvement respect to the corresponding deterministic model, providing in most cases (three seasons over four) theoretical chlorophyll a distributions in a better agreement with the experimental findings.

Moreover, we obtained two "reduced" versions of the original five-population model, studying the spatio-temporal behaviour of only one (Pelagophytes) and only two (Pelagophytes and Prochlorococcus HL) of the five picophytoplankton groups. We note that the two populations chosen are the same used for the analyses presented in Sections 3 and 4. In both cases (one- and two- population "reduced" models), the statistical tests performed on numerical results showed a much worse agreement with experimental data respect to the five-population model. In particular, numerical results (here not reported) indicated that the high concentration of chlorophyll $a$ in the shallower layers, during autumn and winter, can be explained only if contributions of Synechococcus and Haptophytes are considered. On the other side, the correct theoretical chlorophyll-a distributions can not be reproduced in springer and summer, without taking into account Prochlorococcus HL. These findings indicate that, in view of obtaining, in the marine site investigated, a correct and exhaustive description of the spatio-temporal dynamics of chlorophyll distributions, all five populations have to be considered.

In order to better analyze the effects of random fluctuations on the phytoplankton dynamics, we study the behaviour of the magnitude, depth and width of the DCM as a function of the noise intensity in all sampling periods (see Fig. 9).

The numerical results show that, for higher values of the noise intensity $\sigma_{R}$, in November and February the magnitude of the DCM slightly increases (see panels a and d of Fig. 9), while the width remains constant in November and decreases in February (see panels b and e). Conversely, in April we observe a slight decrease of the magnitude of the DCM and a nonmonotonic behaviour of the width of the DCM as a function of the noise intensity (see panels $g$ and $i$ ). This behaviour suggests that the width and magnitude of the DCM are strictly connected with each other during early spring. 

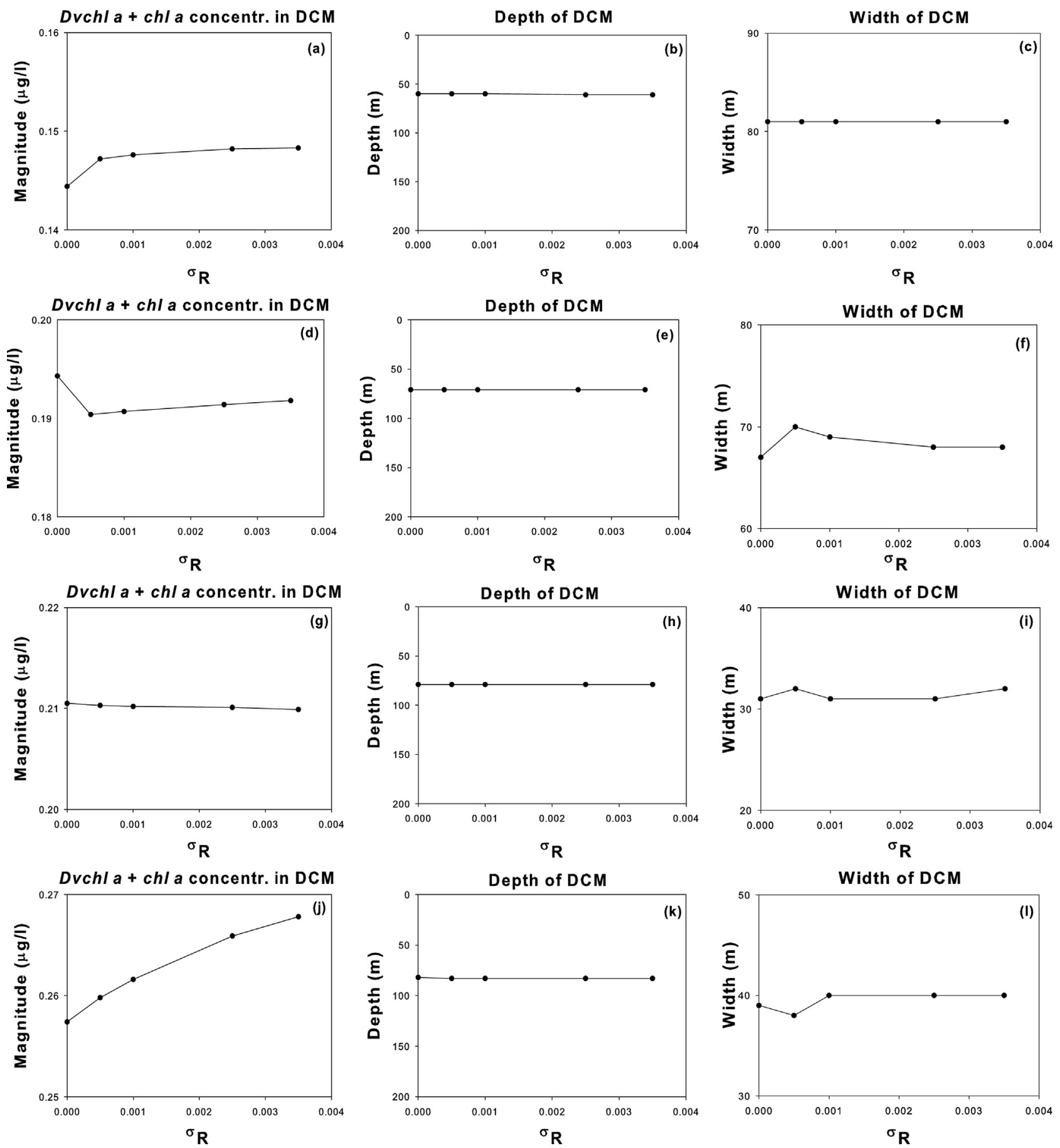

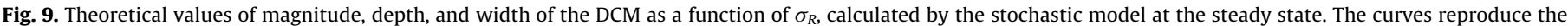

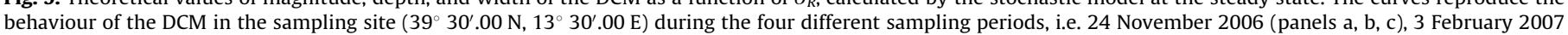
(panels d, e, f), 22 April 2007 (panels g, h, i), and 9 June 2007 (panels j, k, l).

This relation is also observed for lower values of the noise intensity $\sigma_{R}$ in the winter season, when high values of the vertical turbulent diffusivity in the upper mixed layer amplify the effects of the environmental random fluctuations. The numerical results show also that in June larger values of $\sigma_{R}$ cause a strong increase of the magnitude of the DCM (see panel $\mathrm{j}$ ), with an initial nonmonotonic behaviour of its width which remains constant for larger values of $\sigma_{R}$ (see panel 1). Finally we note that in all seasons the depth of the DCM remains constant for all values of noise intensity considered (see panels $\mathrm{b}, \mathrm{e}, \mathrm{h}$, and $\mathrm{k}$ ).

We conclude this section saying that the discrepancies between theoretical and experimental chlorophyll a distributions, previously obtained by the deterministic reaction-diffusion-taxis model (Valenti et al., 2015), can be ascribed to: (i) the lack of experimental data for the randomly fluctuating velocity components, required to estimate the vertical turbulent diffusivity in the deeper layers during the year; (ii) the assumption that the nutrient halfsaturation coefficients are constant during the whole year, without taking into account their continuous changes due to the environmental random fluctuations. The results presented in this section indicate that, in the absence of experimental values for some variables, such as vertical turbulent diffusivity and nutrient half-saturation coefficients, the stochastic model can reproduce better than the deterministic one the spatio-temporal dynamics of 
the chlorophyll a concentration. This is due to the fact that the stochastic model takes into account environmental random fluctuations, affecting both biological and physical variables, and provides therefore a more realistic dynamics of the ecosystem.

\section{Discussion and conclusions}

In this work we presented three theoretical studies, based on stochastic advection-diffusion-reaction models, analyzing the spatio-temporal dynamics of picophytoplankton populations in different ecosystems (Valenti et al., 2004b, 2012; Liu et al., 2008; Denaro et al., 2013a,b,c; Denaro, 2014). In a preliminary deterministic analysis (here not reported) we studied the advection-diffusion-reaction models, focalizing the attention on the role of the advection process in our marine ecosystems, which are assumed to be heterogenous habitats (Vergni et al., 2012). In particular, we observed that the effects of the advection (taxis) term on the phytoplankton dynamics could be considered negligible, because the reduced size of the picophytoplankton cells implies low sinking (swimming) velocity for each species (Raven, 1998). This feature reduces the motility of each picophytoplankton group, inhibiting their invasion process towards the biomass production layers of the other groups (Klausmeier and Litchman, 2001; Vergni et al., 2012).

Afterwards, we modified the deterministic models to show that random fluctuations of environmental variables can influence significantly the spatio-temporal dynamics of the chlorophyll a concentration in real marine ecosystems. In particular, we were able to reproduce the chlorophyll a distributions measured in two different sites of the Mediterranean Sea, taking into account the biological and environmental characteristics of each ecosystem. Initially, we have investigated the phytoplankton dynamics of one population and two populations in a site of the Sicily Channel during the summer season, keeping constant the biological and physical parameters during our simulations. Afterwards, we analyzed the spatio-temporal behaviour of five picophytoplankton groups in a site of the Tyrrhenian Sea during four different periods of the year, taking into account the seasonal changes of the environmental variables. Specifically, on the basis of experimental data, we reproduced the spatio-temporal behaviour of vertical turbulent diffusivity and light intensity, and analyzed their effects on the phytoplankton dynamics.

The phytoplankton populations analyzed throughout this work belong to two domains, i.e. picoeukaryotes and picoprokaryotes, which account about for $80 \%$ of the total chlorophyll on average in the Mediterranean Sea and represent the picophytoplankton fraction. In general, the characteristics of picophytoplankton groups, such as shape, size, average abundance and sinking (or swimming) velocity, are unknown for the most part of seas and oceans. As a consequence, several authors modeled the vertical profiles of the phytoplankton groups, without considering their real biological parameters, only on the basis of previous mathematical tools. In recent works (Valenti et al., 2012, 2015; Denaro et al., 2013a,b,c; Denaro, 2014), however, we modified this approach by performing a careful study on the picophytoplankton groups involved in the two marine ecosystems investigated, and devising models which take into account their biological features.

According to previous works, in the first marine ecosystem analyzed (a site of the Strait of Sicily), we obtained the spatiotemporal behaviour of the cell concentrations, (i) choosing the parameters in such a way to avoid, in the picophytoplankton populations, the appearance of intrinsic oscillations, (ii) keeping the system far from the chaos (Ryabov and Blausius, 2008; Ryabov et al., 2010).

Conversely, in the second marine ecosystem (a site of the Tyrrhenian Sea), we estimated preliminarily the physical variables in all seasons on the basis of the experimental data acquired in situ (Monin and Yaglom, 1971; Oakey and Elliott, 1982; Denman and Gargett, 1983; Peters et al., 1988; Massel, 1999; Valenti et al., 2015), while the biological parameters were fixed according to previous experimental findings (Raven et al., 2005; Veldhuis et al., 2005; Thingstad and Sakshaugh, 1990; Quevedo and Anadón, 2001; Timmermans et al., 2005; Bertilsson et al., 2003). Also in this case, however, the parameter setting determined phytoplankton dynamics with neither oscillations nor chaos, in agreement with numerical results obtained by other authors (Huisman and Weissing, 1999; Huisman et al., 2006; Ryabov et al., 2010). Moreover, the results of our analysis allowed to verify that the "paradox of the plankton" theory can not be applied to the marine ecosystem analyzed due to its spatial heterogeneity and temporal variability of the physical parameters (Huisman and Weissing, 1999).

It is worth recalling that, unlike the other authors who dealt with modelling of phytoplankton dynamics (Klausmeier and Litchman, 2001; Huisman and Weissing, 1999; Huisman et al., 2002, 2006; Ryabov and Blausius, 2008; Ryabov et al., 2010; Ryabov, 2012), we exploited the conversion rates from cell to chlorophyll concentration to validate the theoretical distributions, obtained by the stochastic models, comparing them with experimental chlorophyll profiles. In particular, the agreement between numerical results and experimental data has been checked by performing $\chi^{2}$ and, in some cases, KolmogorovSmirnov tests.

For the marine site located in the Strait of Sicily the theoretical chlorophyll distributions, obtained using a one-population model, were quantitatively compared with experimental findings, by performing $\chi^{2}$ test. The results showed that the presence of a multiplicative noise source in the differential equation for the nutrient (phosphorus) dynamics improves the agreement between the theoretical and experimental profiles of chlorophyll concentration respect to the deterministic case. Moreover we found that, as expected, the picophytoplankton populations tend to disappear due to the presence of the multiplicative noise source, when the strength of the random fluctuations increases.

The dynamics of the same ecosystem were also analyzed by a stochastic two-population model. According to the procedure followed for the one-population analysis, as a first step we studied the theoretical results obtained by inserting only a noise source, which acts directly on the dynamics of the nutrient. In this case, the theoretical profile of the total chl $a$ and Dvchl a concentration, obtained for a suitable noise intensity, was in a very good agreement with the experimental one. In particular, the results of the statistical tests were much better than those obtained by using both the stochastic one-population model and the deterministic two-population model. Afterwards, we considered the simultaneous presence of noise sources acting on the picophytoplankton groups and nutrient. At this aim, we inserted terms of multiplicative noise in all three stochastic differential equations of our model. In this case, for suitable noise intensities, the $\chi^{2}$ goodness-of-fit test exhibited in the site investigated a value much lower than those obtained by considering only one noise source (Denaro et al., 2013b,c; Denaro, 2014). Moreover, similarly to the results obtained for the one-population model, a rapid extinction of both picophytoplankton populations was observed for higher noise intensities.

This two-population analysis, introduced by Denaro et al. (2013b,c), allowed to describe the overall role of the environmental noise on the phytoplankton dynamics, according to the following scheme: (i) indirect influence through the stochastic dynamics of the nutrient concentration; (ii) additional presence of external noise sources which act directly on the phytoplankton dynamics. 
Finally, we presented a new study performed using a stochastic five-population model, and taking into account the seasonal behaviour of some environmental variables (Goryachev et al., 2005; Maye et al., 2007; Valenti et al., 2015). In particular, we modified a previous deterministic five-population model (Denaro, 2014; Valenti et al., 2015) by inserting a term of multiplicative noise in the differential equation for the phosphorus dynamics.

It is worth underlining that, in this case, the numerical results were obtained using for the physical variables values estimated in accordance with experimental data. From a qualitative point of view, this approach allowed to better understand the mechanism which triggers the upwelling of nutrients along the water column, and analyze the effects of the mixing on the phytoplankton dynamics (Ryabov et al., 2010; Patti et al., 2010; Basilone et al., 2013; Rinaldi et al., 2014; Valenti et al., 2015). In particular, it was observed that an increase of vertical turbulent diffusivity in UML during autumn and winter supports the upwelling of nutrients. As a consequence, an increase of the total chl $a$ and Dvchl $a$ concentration in the shallower layers occurs (Valenti et al., 2015), due to the growth of Synechococcus and Haptophytes. Vice versa, the numerical results showed a strong decrease of the total chl $a$ and Dvchl a concentration in the upper mixed layers during spring and summer, due to a reduced mixing above the thermocline.

From a quantitative point of view, the $\chi^{2}$ goodness-of-fit test indicated the presence of a good agreement between experimental and theoretical findings during the whole period analyzed, even if the best value of the reduced chi-square in each season was reached for a different noise intensity. Specifically, in accordance with previous studies (Denaro et al., 2013a,b), the $\chi^{2}$ test showed that the stochastic model reproduces the experimental data better than the deterministic one in three sampling periods. Conversely, in late spring the best reduced chi-square was obtained by the deterministic model. This can be explained considering that in late spring (June) the random fluctuations of environmental parameters are strongly reduced along the whole water column (Ribera d'Alcalà et al., 2009; Denis et al., 2010; Mella-Flores et al., 2011; La Ferla et al., 2012; Valenti et al., 2015).

Moreover, we calculated theoretical distributions of chlorophyll concentration by using one- and two-population "reduced" models, obtained as simplified versions of the initial fivepopulation model. Also in these two cases we compared the theoretical profiles with the corresponding experimental distributions collected in the Tyrrhenian Sea, observing a worse agreement respect to the five-population model. Therefore, we can conclude that all main phytoplankton groups have to be taken into account to describe correctly the seasonal changes in the spatial distributions of the total chlorophyll concentration. In this sense, the stochastic five-population model seems to be the best mathematical tool to reproduce and eventually predict the ecosystem dynamics.

In general, the analysis performed suggests that an appropriate modeling needs a deep knowledge of the time behaviour of environmental and biological variables such as: (i) velocity components subject to random fluctuations during the year; (ii) nutrient half-saturation constants, $K_{R_{i}}$, significantly influenced by the seasonal changes. Moreover, the analysis confirmed some experimental and theoretical results obtained in recent works (Bengfort et al., 2014; Peters and Marrasé, 2000): (i) environments with intermediate values of turbulence are responsible for changes in the carrying capacity, causing positive effects in the growth rates of phytoplankton populations (Bengfort et al., 2014); (ii) strongly turbulent regimes can determine, in principle, negative effects on the phytoplankton growth. However, this negative influence has been never observed in real situations, appearing only in aquatic environments with artificial turbulence (Peters and Marrasé, 2000).

In conclusion, the stochastic models presented in this work showed to be powerful tools to describe the dynamics of real ecosystems. These, due to their features of open systems, need in fact to be modeled considering the continuous random and deterministic perturbations coming from the environment.

A possible extension of these models could be the inclusion of higher trophic levels, such as zooplankton populations, in view of devising a global model to reproduce the seasonal dynamics of fish species (Liu et al., 2008). This could help to devise strategies to prevent the decline of the primary production (phytoplankton biomass), with the consequent decrease of fish species due to the global warming (Kiorboe, 2008; Denaro et al., 2013b; Denaro, 2014; Valenti et al., 2015).

\section{Acknowledgements}

Authors acknowledge the financial support by Ministry of University, Research and Education of Italian Government, Project PON02_00451_3362121 "PESCATEC - Sviluppo di una Pesca Siciliana Sostenibile e Competitiva attraverso l'Innovazione Tecnologica”, and Project PON02_00451_3361909 “SHELF-LIFE Utilizzo integrato di approcci tecnologici innovativi per migliorare la shelf-life e preservare le proprietà nutrizionali di prodotti agroalimentari".

\section{References}

Basilone, G., Bonanno, A., Patti, B., Mazzola, S., Barra, M., Cuttitta, A., McBride, R., 2013. Spawning site selection by European anchovy (Engraulisencrasicolus) in relation to oceanographic conditions in the Strait of Sicily. Fish. Oceanogr. 22 (4), 309-323.

Bengfort, M., Feudel, U., Hilker, F.M., Malchow, H., 2014. Plankton blooms and patchiness generated by heterogeneous physical environments. Ecol. Complex. 20, 185-194.

Berti, S., López, C., Vergni, D., Vulpiani, A., 2007. Discreteness effects in a reacting system of particles with finite interaction radius. Phys. Rev. E 76, 031139 (1-7).

Bertilsson, S., Berglund, O., Karl, D.M., Chisholm, S.W., 2003. Elemental composition of marine Prochlorococcus and Synechococcus: implications for the ecological stoichiometry of the sea. Limnol. Oceanogr. 48, 1721-1731.

Beversdorf, L., Miller, T., McMahon, K., 2013. The role of nitrogen fixation in cyanobacterial bloom toxicity in a temperate, eutrophic lake. PLoS ONE 8 (2), e56103.

Bjørnstad, O.N., Grenfell, B.T., 2001. Noisy clockwork: time series analysis of population fluctuations in animals. Science 293, 638-643.

Bonanno, A., Placenti, F., Basilone, G., Mifsud, R., Genovese, S., Patti, B., Di Bitetto, M., Aronica, S., Barra, M., Giacalone, G., Ferreri, R., Fontana, I., Buscaino, G., Tranchida, G., Quinci, E., Mazzola, S., 2014. Variability of water mass properties in the Strait of Sicily in summer period of 1998-2013. Ocean Sci. 10, 759-770.

Bonanno, A., Zgozi, S., Cuttitta, A., El Turki, A., Di Nieri, A., Ghmati, H., Basilone, G., Aronica, S., Hamza, M., Barra, M., Genovese, S., Falco, F., Knittweis, L., Mifsud, R., Patti, B., Bahri, T., Giacalone, G., Fontana, I., Tranchida, G., Mazzola, S., 2013. Influence of environmental variability on anchovy early life stages (Engraulis encrasicolus) in two different areas of the Central Mediterranean sea. Hydrobiologia 701, 273-287.

Bonanno, G., Valenti, D., Spagnolo, B., 2007. Mean escape time in a system with stochastic volatility. Phys. Rev. E 75, 016106 (1-8).

Bopp, L., Monfray, P., Aumont, O., Dufresne, J.L., Treut, H.L., Madec, G., Terray, L., Orr, J.C., 2001. Potential impact of climate change on marine export production. Global. Biogeochem. Cy. 15, 81-99.

Bougaran, G., Bernard, O., Sciandra, A., 2010. Modeling continuous cultures of microalgae colimited by nitrogen and phosphorus. J. Theor. Biol. 265, 443-454.

Brunet, C., Casotti, R., Aronne, B., Vantrepotte, V., 2003. Measured photophysiological parameters used as tools to estimate vertical water movements in the coastal Mediterranean. J. Plankton Res. 25, 1413-1425.

Brunet, C., Casotti, R., Vantrepotte, V., 2008. Phytoplankton diel and vertical variability in photobiological responses at a coastal station in the Mediterranean Sea. J. Plankton Res. 30, 645-654.

Brunet, C., Casotti, R., Vantrepotte, V., Conversano, F., 2007. Vertical variability and diel dynamics of picophytoplankton in the Strait of Sicily, Mediterranean Sea, in summer. Mar. Ecol. Prog. Ser. 346, 15-26.

Brunet, C., Casotti, R., Vantrepotte, V., Corato, F., Conversano, F., 2006. Picophytoplankton diversity and photoacclimation in the Strait of Sicily (Mediterranean Sea) in summer, I. Mesoscale variations. Aquat. Microb. Ecol. 44, 127-141. 
Caruso, A., Gargano, M.E., Valenti, D., Fiasconaro, A., Spagnolo, B., 2005. Cyclic fluctuations, climatic changes and role of noise in planktonic foraminifera in the Mediterranean Sea. Fluct. Noise Lett. 5, L349-L355.

Casotti, R., Brunet, C., Aronne, B., Ribera d'Alcalà, M., 2000. Mesoscale features of phytoplankton and planktonic bacteria in a coastal area as induced by external water masses. Mar. Ecol. Prog. Ser. 195, 15-27.

Casotti, R., Landolfi, A., Brunet, C., D’Ortenzio, F., Mangoni, O., Ribera d'Alcalà, M., 2003. Composition and dynamics of the phytoplankton of the Ionian Sea (Eastern Mediterranean). J. Geophys. Res. 108 (C9), 8116

Chichigina, O., Valenti, D., Spagnolo, B., 2005. A simple noise model with memory for biological systems. Fluct. Noise Lett. 5, L243-L250.

Chichigina, O.A., 2008. Noise with memory as a model of lemming cycles. Eur. Phys. J. B 65, 347-352.

Chichigina, O.A., Dubkov, A.A., Valenti, D., Spagnolo, B., 2011. Stability in a system subject to noise with regulated periodicity. Phys. Rev. E 84, 021134 (1-10).

Cuttitta, A., Carini, V., Patti, B., Bonanno, A., Basilone, G., Mazzola, S., García Lafuente, J., García, A., 2003. Anchovy egg and larval distribution in relation to biological and physical oceanography in the Strait of Sicily. Hydrobiologia 503, 117-120.

Denaro, G., 2014. Stochastic models for phytoplankton dynamics in marine ecosystem. PhD Thesis. Università di Palermo, Italy unpublished.

Denaro, G., Valenti, D., La Cognata, A., Spagnolo, B., Bonanno, A., Basilone, G., Mazzola, S., Zgozi, S., Aronica, S., Brunet, C., 2013a. Spatio-temporal behaviour of the deep chlorophyll maximum in Mediterranean Sea: development of a stochastic model for picophytoplankton dynamics. Ecol. Complex. 13, 21-34.

Denaro, G., Valenti, D., Spagnolo, B., Basilone, G., Mazzola, S., Zgozi, S., Aronica, S. Bonanno, A., 2013b. Dynamics of two picophytoplankton groups in Mediterranean Sea: analysis of the deep chlorophyll maximum by a stochastic advectionreaction-diffusion model. PLoS ONE 8 (6), e66765.

Denaro, G., Valenti, D., Spagnolo, B., Bonanno, A., Basilone, G., Mazzola, S., Zgozi, S. Aronica, S., 2013c. Stochastic dynamics of two picophytoplankton populations in a real marine ecosystem. Acta Phys. Pol. B 44, 977-990.

Denis, M., Thyssen, M., Martin, V., Manca, B., Vidussi, F., 2010. Ultraphytoplankton basin-scale distribution in the eastern Mediterranean Sea in winter: link to hydrodynamism and nutrients. Biogeosciences 7, 2227-2244.

Denman, K.L., Gargett, A.E., 1983. Time and space scales of vertical mixing and advection of phytoplankton in the upper ocean. Limnol. Oceanogr. 28, 801-815.

Dimier, C., Brunet, C., Geider, R., Raven, J., 2009. Growth and photoregulation dynamics of the picoeukaryote Pelagomonascalceolata in fluctuating light. Limnol. Oceanogr. 54, 823-836.

Dubkov, A.A., Spagnolo, B., 2005. Acceleration of diffusion in randomly switching potential with supersymmetry. Phys. Rev. E 72, 041104 (1-8).

Durrett, R., Levin, S., 1994. The importance of being discrete (and spatial). Theor. Popul. Biol. 46, 363-394.

Fiasconaro, A., Valenti, D., Spagnolo, B., 2006. Asymptotic regime in N random interacting species. Eur. Phys. J. B 50, 189-194.

Fogg, G.E., 1991. The phytoplanktonic ways of life. New Phytol. 118, 191-232.

Garczarek, L., Dufresne, A., Rousvoal, S., West, N.J., Mazard, S., Marie, D., Claustre, H., Raimbault, P., Post, A.F., Scanlan, D.J., Partensky, F., 2007. High vertical and low horizontal diversity of prochlorococcus ecotypes in the Mediterranean Sea in summer. FEMS Microbiol. Ecol. 60, 189-206.

Gasparini, G.P., Bonanno, A., Zgozi, S., Basilone, G., Borghini, M., Buscaino, G. Cuttitta, A., Essarbout, N., Mazzola, S., Patti, B., Ramadan, A.B., Schroeder, K., Bahri, T., Massa, F., 2008. Evidence of a dense water vein along the Libyan continental margin. Ann. Geophys. 26, 1-6.

Giuffrida, A., Valenti, D., Ziino, G., Spagnolo, B., Panebianco, A., 2009. A stochastic interspecific competition model to predict the behaviour of Listeriamonocytogenes in the fermentation process of a traditional Sicilian salami. Eur. Food Res. Technol. 228, 767-775.

Goryachev, A., Toh, D.J., Wee, K.B., Lee, T., Zhang, H.B., Zhang, L.H., 2005. Transition to quorum sensing in an agrobacterium population: a stochastic model. PLoS Comput. Biol. 1 (4), e37.

Grasshoff, K., 1976. Methods of Seawater Analysis. Verlang Chemie, New York.

Grenfell, B.T., Wilson, K., Finkenstädt, B.F., Coulson, T.N., Murray, S., Albon, S.D., Pemberton, J.M., Clutton-Brock, T.H., Crawley, M.J., 1998. Noise and determinism in synchronized sheep dynamics. Nature 394, 674-677.

Hickman, A., Dutkiewicz, S., Williams, R., Follows, M., 2010. Modelling the effects of chromatic adaptation on phytoplankton community structure in the oligotrophic ocean. Mar. Ecol. Prog. Ser. 406, 1-17.

Huisman, J., Arrays, M., Ebert, U., Sommeijer, B., 2002. How do sinking phytoplankton species manage to persist? Am. Nat. 159, 245-254.

Huisman, J., Thi, N.N.P., Karl, D.M., Sommeijer, B., 2006. Reduced mixing generates oscillations and chaos in the oceanic deep chlorophyll maximum. Nature 439, $322-325$.

Huisman, J., Weissing, F., 1999. Biodiversity of plankton by species oscillations and chaos. Nature 402, 407-410.

Huisman, J., Weissing, F.J., 1994. Light-limited growth and competition for light in well-mixed aquatic environments: an elementary model. Ecology 75, 507-520.

Hundsdorfer, W., Verwer, J.G., 2003. Numerical solution of time-dependent advection-diffusion-reaction equations. In: Springer Series in Computational MathematicsSpringer-Verlag, Berlin.

Jennings, S., Kaiser, M.J., Reynolds, J.D., 2001. Marine Fisheries Ecology. Blackwell Science, Oxford.

Justić, D., Rabalais, N.N., Turner, R.E., 2002. Modeling the impacts of decadal changes in riverine nutrient fluxes on coastal eutrophication near the Mississippi River Delta. Ecol. Model. 152, 33-46.
Karsenti, E., Acinas, S., Bork, P., Bowler, C., Vargas, C.D., Raes, J., Sullivan, M., Arendt, D., et al., 2011. A holistic approach to marine eco-systems biology. PLoS Biol. 9 (10), e1001177.

Kiørboe, T., 2008. A Mechanistic Approach to Plankton Ecology. Princeton University Press.

Kirk, J.T.O., 1994. Light and Photosynthesis in Aquatic Ecosystems, 2nd ed. Cambridge University Press.

Klausmeier, C.A., Litchman, E., 2001. Algal games: the vertical distribution of phytoplankton in poorly mixed water columns. Limnol. Oceanogr. 46, 19982007.

Klausmeier, C.A., Litchman, E., Levin, S.A., 2007. A model of flexible uptake of two essential resources. J. Theor. Biol. 246, 278-289.

La Barbera, A., Spagnolo, B., 2002. Spatio-temporal patterns in population dynamics. Physica A 314, 120-124.

La Cognata, A., Valenti, D., Dubkov, A., Spagnolo, B., 2010. Dynamics of two competing species in the presence of levy noise sources. Phys. Rev. E 82, $011121,1-8$.

La Ferla, R., Maimone, G., Azzaro, M., Conversano, F., Brunet, C., Cabral, A.S. Paranhos, R., 2012. Vertical distribution of the prokaryotic cell size in the Mediterranean Sea. Helgol. Mar. Res. 66 (4), 635-650.

Liu, Q.X., Jin, Z., Li, B.L., 2008. Resonance and frequency-locking phenomena in spatially extended phytoplankton-zooplankton system with additive noise and periodic forces. J. Stat. Mech. Theory E. 5, P05011.

Massel, S.R., 1999. Fluid Mechanics for Marine Ecologists. Springer-Verlag, Berlin Heidelberg.

Maye, A., Hsieh, C.H., Sugihara, G., Brembs, B., 2007. Order in spontaneous behavior. PLOS ONE 2 (5), e443.

Mei, Z.P., Finkel, Z.V., Irwin, A.J., 2009. Light and nutrient availability affect the sizescaling of growth in phytoplankton. J. Theor. Biol. 259, 582-588.

Melbourne-Thomas, J., Constable, A., Wotherspoon, S., Raymond, B., 2013. Testing paradigms of ecosystem change under climate warming in antarctica. PLoS ONE 8 (2), e55093.

Mella-Flores, D., Mazard, S., Humily, F., Partensky, F., Mahé, F., Bariat, L., Courties, C. Marie, D., Ras, J., Mauriac, R., Jeanthon, C., Bendif, E.M., Ostrowski, M., Scanlan, D.J., Garczarek, L., 2011. Is the distribution of Prochlorococcus and Synechococcus ecotypes in the Mediterranean Sea affected by global warming? Biogeosciences 8 (9), 2785-2804.

Monin, A.S., Yaglom, A.M., 1971. Statistical Fluid Mechanics. Massachusetts Institute of Technology.

Moore, L.R., Goericke, R., Chisholm, S.W., 1995. Comparative physiology of synechococcus and prochlorococcus: influence of light and temperature on growth, pigments, fluorescence and absorptive properties. Mar. Ecol. Prog. Ser. 116 259-275.

Morel, A., 1997. Consequences of a Synechococcus bloom upon the optical properties of oceanic (case 1) waters. Limnol. Oceanogr. 42 (8), 1746-1754.

Nakamura, Y., Hayakawa, N., 1991. Modelling of thermal stratification in lakes and coastal seas. In: Hydrology of Natural and Manmade Lakes, IAHS Publ, pp. 227 236.

Nishimura, H., Nakamura, Y., 1987. A new method of estimating vertical diffusion coefficient. Cont. Shelf Res. 7, 1245-1256.

Norberg, J., 2004. Biodiversity and ecosystem functioning: a complex adaptive systems approach. Limnol. Oceanogr. 49, 1269-1277.

Oakey, N.S., Elliott, J.A., 1982. Dissipation within the surface mixed layer. J. Phys. Oceanogr. 12, 171-185.

Olson, R.J., Zettler, E.R., DuRand, M.D., 1993. Phytoplankton analysis using flow cytometry.In: Handbook of Methods in Aquatic Microbial Ecology, Lewis Publishers, Boca Raton, FL, USA, pp. 175-186.

Patti, B., Guisande, C., Bonanno, A. Basilone, G., Cuttitta, A., Mazzola, S., 2010. Role of physical forcings and nutrient availability on the control of satellite-based chlorophyll $a$ concentration in the coastal upwelling area of the Sicilian Channel. Sci. Mar. 74 (3), 577-588.

Peters, F., Marrasé, C., 2000. Effects of turbulence on plankton: an overview of experimental evidence and some theoretical considerations. Mar. Ecol. Prog. Ser. 205, 291-306

Peters, H., Gregg, M.C., Toole, J.M., 1988. On the parameterization of Equatorial Turbulence. J. Geophys. Res. 93, 1199-1218.

Prézelin, B.B., Tilzer, M.M., Schofield, O., Haese, C., 1991. The control of the production process of phytoplankton by the physical structure of the aquatic environment with special reference to its optical properties. Aquat. Sci. 53,136186.

Quevedo, M., Anadón, R., 2001. Protist control of phytoplankton growth in the subtropical north-east Atlantic. Mar. Ecol. Prog. Ser. 221, 20-38.

Raven, J.A., 1998. The twelfth tansley lecture, Small is beautiful: the picophytoplankton. Funct. Ecol. 12, 503-513.

Raven, J.A., Finkel, Z.V., Irwin, A.J., 2005. Picophytoplankton: bottom-up an topdown controls on ecology and evolution. J. Geophys. Res. 55, 209-215.

Ribera d'Alcalà, M., Brunet, C., Conversano, F., Corato, F., Lavezza, R., 2009. Nutrient and pigment distributions in the southern Tyrrhenian Sea during mid-summe and late fall 2005. Deep-Sea Res. II 56, 676-686.

Ribera d'Alcalà, M., Civitarese, G., Conversano, F., Lavezza, R., 2003. Nutrient ratios and fluxes hint at overlooked processes in the Mediterranean Sea. J. Geophys. Res. 108 (C9), 8106.

Rinaldi, E., Buongiorno Nardelli, B., Volpe, G., Santoleri, R., 2014. Chlorophyll distribution and variability in the Sicily Channel (Mediterranean Sea)as seen by remote sensing data. Cont. Shelf Res. 77, 61-68. 
Rippka, R., Coursin, T., Hess, W., Lichtle, C., Scanlan, D.J., Palinska, K.A., Iteman, I., Partensky, F., Houmard, J., Herdman, M., 2000. Prochlorococcusmarinus Chisholm et al. 1992 subsp. pastoris subsp. nov. strain PCC 9511, the first axenic chlorophyll $a_{2} / b_{2}$-containing cyanobacterium (Oxyphotobacteria). Int. J. Syst. Evol. Microbiol. 50, 1833-1847.

Roache, P.J., 1976. Computational Fluid Dynamics. Hermosa Publishers, Albuquerque, New Mexico.

Roache, P.J., 1998. Fundamentals of Computational Fluid Dynamics. Hermosa Publishers, Albuquerque, New Mexico.

Ryabov, A., 2012. Phytoplankton competition in deep biomass maximum. Theor. Ecol. 5, 373-385.

Ryabov, A., Blasius, B., 2011. A graphical theory of competition on spatial resource gradients. Ecol. Lett. 14, 220-228.

Ryabov, A.B., Blausius, B., 2008. Population growth and persistence in a heterogeneous environment: the role of diffusion and advection. Math. Model. Nat. Phenom. 3, 42-86.

Ryabov, A.B., Rudolf, L., Blasius, B., 2010. Vertical distribution and composition of phytoplankton under the influence of an upper mixed layer. J. Theor. Biol. 263, $120-133$.

Sarmiento, J.L., Slater, R., Barber, R., Bopp, L., Doney, S.C., Hirst, A.C., Kleypas, J., Matear, R., Mikolajewicz, U., Monfray, P., Soldatov, V., Spall, S.A., Stouffer, R., 2004. Response of ocean ecosystems to climate warming. Global. Biogeochem. Cy. 18.

Schmittner, A., 2005. Decline of the marine ecosystem caused by a reduction in the Atlantic overturning circulation. Nature 434, 628-633.

Shigesada, N., Okubo, A., 1981. Effects of competition and shading in planktonic communities. J. Math. Biol. 12, 311-326.

Spagnolo, B., Cirone, M., La Barbera, A., de Pasquale, F., 2002. Noise induced effects in population dynamics. J. Phys. Condens. Matter 14, 2247-2255.

Spagnolo, B., Fiasconaro, A., Valenti, D., 2003. Noise induced phenomena in LotkaVolterra systems. Fluct. Noise Lett. 3, L177-L185.

Spagnolo, B., La Barbera, A., 2002. Role of the noise on the transient dynamics of an ecosystem of interacting species. Physica A 315, 114-124.

Spagnolo, B., Valenti, D., Fiasconaro, A., 2004. Noise in ecosystems: a short review. Math. Biosci. Eng. 1, 185-211.

Spagnolo, B., Valenti, D., Fiasconaro, A., 2005. Transient behavior of a population dynamical model. Prog. Theor. Phys. Suppl. 157, 312-316.

Thi, N.N.P., Huisman, J., Sommeijer, B.P., 2005. Simulation of three-dimensional phytoplankton dynamics: competition in light-limited environments. J. Comput. Appl. Math. 174, 57-77.

Thingstad, T.F., Rassoulzadegan, F., 1995. Nutrient limitations, microbial food webs, and biological C-pumps: Suggested interactions in a P-limited Mediterranean. Mar. Ecol. Prog. Ser. 117, 299-306.
Thingstad, T.F., Sakshaugh, E., 1990. Control of phytoplankton growth in nutrient recycling ecosystems. Theory and terminology. Mar. Ecol. Prog. Ser. 63, 261272.

Tian, C., Zhang, L., 2013. Delay-driven irregular spatiotemporal patterns in a plankton system. Phys. Rev. E 88, 012713 (1-6).

Timmermans, K.R., van der Wagt, B., Veldhuis, M.J.W., Maatman, A., de Baar, H.J.W., 2005. Physiological responses of three species of marine pico-phytoplankton to ammonium, phospahte, iron and light limitation. J. Sea Res. 53, 109-120.

Tveito, A., Winther, R., 1998. Introduction to Partial Differential Equations: A Computational Approach. Springer-Verlag, New York.

Valenti, D., Denaro, G., La Cognata, A., Spagnolo, B., Bonanno, A., Mazzola, S., Zgozi, S., Aronica, S., 2012. Picophytoplankton dynamics in noisy marine environment. Acta Phys. Pol. B 43, 1227-1240.

Valenti, D., Denaro, G., Spagnolo, B., Conversano, F., Brunet, C., 2015. How diffusivity, thermocline and incident light intensity modulate the dynamics of deep chlorphyll maximum in tyrrhenian sea. PLoS ONE 10 (1), e0115468.

Valenti, D., Fiasconaro, A., Spagnolo, B., 2004a. Pattern formation and spatial correlation induced by the noise in two competing species. Acta Phys. Pol. B 35, 1481-1489.

Valenti, D., Fiasconaro, A., Spagnolo, B., 2004b. Stochastic resonance and noise delayed extinction in a model of two competing species. Physica A 331, 477486.

Valenti, D., Schimansky-Geier, L., Sailer, X., Spagnolo, B., 2006. Moment Equations for a Spatially Extended System of Two Competing Species. Eur. Phys. J. B 50, 199-203.

Valenti, D., Spagnolo, B., Bonanno, G., 2007. Hitting time distributions in financial markets. Physica A 382, 311-320.

Veldhuis, M.J.W., Timmermans, K.R., Croot, P., Van Der Wagt, B., 2005. Picophytoplankton; a comparative study of their biochemical composition and photosynthetic properties. J. Sea Res. 53, 7-24.

Veldman, A.E.P., 2001. Computational Fluid Dynamics. Lecture Notes, University of Groningen, The Netherlands.

Vergni, D., Iannaccone, S., Berti, S., Cencini, M., 2012. Invasions in heterogeneous habitats in the presence of advection. J. Theor. Biol. 301, 141-152.

Weston, K., Fernand, L., Mills, D.K., Delahunty, R., Brown, J., 2005. Primary production in the deep chlorophyll maximum of the central North Sea. J. Plankton Res. 27, 909-922.

Yeo, S.K., Huggett, M., Eiler, A., Rappè, M., 2013. Coastal bacterioplankton community dynamics in response to a natural disturbance. PLoS ONE 8 (2), e56207.

Zeng, C., Zhang, C., Zeng, J., Luo, H., Tian, D., Zhang, H., Long, F., Xu, Y., 2015. Noisesinduced regime shifts and -enhanced stability under a model of lake approaching eutrophication. Ecol. Complex. 22, 102-108.

Zimmer, C., 1999. Life after chaos. Science 284, 83-86. 